\title{
Protein-protein complexation in bioluminescence
}

\author{
Maxim S. Titushin ${ }^{1}$, Yingang Feng ${ }^{2}$, John Lee ${ }^{3}$, Eugene S. Vysotski ${ }^{4}$, Zhi-Jie Liu ${ }^{1 凶}$ \\ ${ }^{1}$ National Laboratory of Biomacromolecules, Institute of Biophysics, Chinese Academy of Sciences, Beijing 100101, China \\ 2 Qingdao Institute of Bioenergy and Bioprocess Technology, Chinese Academy of Sciences, Qingdao 266101, China \\ 3 Department of Biochemistry and Molecular Biology, University of Georgia, Athens, GA 30602, USA \\ 4 Laboratory of Photobiology, Institute of Biophysics Russian Academy of Sciences, Siberian Branch, Krasnoyarsk 660036, \\ Russia \\ $\bowtie$ Correspondence: zjliu@ibp.ac.cn
}

Received October 23, 2011 Accepted November 7, 2011

\section{ABSTRACT}

In this review we summarize the progress made towards understanding the role of protein-protein interactions in the function of various bioluminescence systems of marine organisms, including bacteria, jellyfish and soft corals, with particular focus on methodology used to detect and characterize these interactions. In some bioluminescence systems, protein-protein interactions involve an "accessory protein" whereby a stored substrate is efficiently delivered to the bioluminescent enzyme luciferase. Other types of complexation mediate energy transfer to an "antenna protein" altering the color and quantum yield of a bioluminescence reaction. Spatial structures of the complexes reveal an important role of electrostatic forces in governing the corresponding weak interactions and define the nature of the interaction surfaces. The most reliable structural model is available for the protein-protein complex of the $\mathrm{Ca}^{2+}$-regulated photoprotein clytin and green-fluorescent protein (GFP) from the jellyfish Clytia gregaria, solved by means of $X$ ray crystallography, NMR mapping and molecular docking. This provides an example of the potential strategies in studying the transient complexes involved in bioluminescence. It is emphasized that structural studies such as these can provide valuable insight into the detailed mechanism of bioluminescence.

KEYWORDS green-fluorescent protein (GFP), photoprotein, luciferase, lumazine protein, Förster resonance energy transfer (FRET), docking

\section{INTRODUCTION}

Living organisms capable of emitting light have been known to mankind since ancient times (Harvey, 1952; Lee, 2008). Bioluminescent organisms such as bacteria, fireflies, jellyfish, worms, fungi, and fish, are widely dispersed on the phylogenetic tree, with a vast majority of species being marine inhabitants. Believed to emerge "independently" many times during evolution, bioluminescence serves vital functions ranging from defense to reproduction, yet in many cases its survival value remains a puzzle (Haddock et al., 2010). The bioluminescence is an enzymatic reaction, where an enzyme, generically referred to as luciferase, catalyzes oxidation of a substrate, generically named luciferin. Both luciferases and luciferins of luminous species belonging to different groups generally display unrelated structures. All known luciferin-luciferase reactions share one common feature, a requirement of oxygen. The chemical mechanism involves oxidation of the luciferin to an electronically excited product, which relaxes to its ground state with radiation of light (Harvey, 1952; Shimomura, 2006). Conversion of the reaction energy into photons goes with a remarkable efficiency.

In addition to luciferases many bioluminescence systems contain supplemental proteins which can be divided into two groups on the basis of their function: "accessory" proteins provide luciferase with luciferin, and "antenna" proteins modulate the bioluminescence color by means of energy transfer. One type of accessory protein is a luciferin-binding protein, which binds luciferin noncovalently in a protein cavity where it is protected from autooxidation by solubilized oxygen. Proper delivery of this luciferin to the luciferase is accomplished through conformational changes of the binding 
protein to render the luciferin available for oxidation in the active site of luciferase. Conformational changes of the binding protein being sensitive to $\mathrm{Ca}^{2+}$ concentration as in the case of Renilla, or $\mathrm{pH}$ value as in the case of dinoflagellates, allow placing the luminescence reactions under control of the neural system (Hastings and Morin, 1969; Anderson et al., 1974; Fogel and Hastings, 1972; Morse et al., 1989). Another accessory protein, NADPH:FMN oxidoreductase, supplies $\mathrm{FMNH}_{2}$ for reaction with oxygen and aldehyde in the active site of bacterial luciferase (Jeffers et al., 2003).

The function of bioluminescence color modulation belongs to the so-called antenna proteins, such as green-fluorescent proteins (GFP) in the bioluminescent coelenterates (Morin and Hastings, 1971; Ward and Cormier, 1979), or lumazine protein and yellow-fluorescent protein in bioluminescent bacteria (O'Kane et al., 1985; Daubner et al., 1987; Macheroux et al., 1987). Fluorescence properties of antenna proteins are due to a bound fluorophore, a molecule known to be involved in intermediary metabolism (bacterial antenna proteins), or a moiety autocatalytically synthesized from amino acid residues of the apo-protein (GFP). The radiative transitions of the antenna protein and the luciferin product of the light reaction undergo weak dipole-dipole coupling of the Förster type, and consequently the antenna protein radiates the energy as its own fluorescence, resulting in a shift of the bioluminescence spectral maximum and change of quantum yield of the bioluminescence reaction. Antenna proteins broaden the range of colors utilized by bioluminescent organisms.

Several lines of evidence indicate that delivery of luciferin from the binding protein to the luciferase as well as modulation of bioluminescence spectra as a result of energy transfer to the antenna proteins, involves protein-protein interactions (Morise et al., 1974; Ward and Cormier, 1976, 1978; Nicolas et al., 1991; Cutler, 1995; Schultz et al., 2005; Titushin et al., 2008, 2010; Stepanyuk et al., 2009; Markova et al., 2010). The interactions are of a transient nature, with $K_{D}$ in the range of $10^{-6}-10^{-3} \mathrm{~mol} / \mathrm{L}$, which highly impedes direct detection of the complexes, or their structural studies with Xray crystallography or NMR methods. For those bioluminescent systems where crystal structures of the individual proteins are known, the topologies of the protein-protein complexes were solved by means of data-driven computer modeling. Among the structures available so far, there are those of the lumazine protein-luciferase complex from the bacteria Photobacterium (Sato et al., 2010), the GFPphotoprotein clytin complex from the jellyfish Clytia (Titushin et al., 2010), and the coelenterazine-binding protein-luciferase complex from the soft coral Renilla (Stepanyuk et al., 2009). The main goal of this review is to cover the mentioned bioluminescence systems, where extensive biochemical studies of the protein-protein interactions have been complemented with structural data, resulting in new insight into the bioluminescence mechanism with regard to the role of the protein-protein complexes. It is also emphasized that computer modeling of the complexes, even being based on comprehensive biophysical data, defines the scope of reliability of the structures, necessitating further structural studies.

\section{BACTERIA}

The bioluminescent bacteria are the most abundant and widely distributed of all bioluminescent organisms and are found in marine, freshwater, and terrestrial environments. These bacteria emit continuous light and are usually found symbiotically associated with a host (fish, squid), commonly as a monoculture contained in a light organ (Hastings and Nealson, 1977; Wilson and Hastings, 1998; Haddock et al., 2010). Bacterial luciferase, one of the most extensively studied flavin monooxygenases, catalyzes the reaction of $\mathrm{FMNH}_{2}, \mathrm{O}_{2}$, and an aliphatic aldehyde to form a high-energy intermediate, which decomposes to FMN and the corresponding carboxylic acid with the emission of blue-green light, a broad spectrum with an emission maximum in the range of 490-509 nm depending on the type of luciferase (Fig. $1 \mathrm{~A}$ and 1D). Luciferase is provided with reduced FMN by an accessory NADPH:FMN oxidoreductase, with which it forms a 1:1 protein-protein complex (Jeffers et al., 2003).

The emission spectra of some bioluminescent bacteria are found blue or red shifted from that of the purified luciferase in vitro reaction, due to accompanying antenna proteins (Fig. 1B and 1C) (Daubner et al., 1987; Lee, 1993). These proteins, lumazine protein and yellow-fluorescent protein (YFP), contain a highly fluorescent ligand (6,7-dimethyl-8-ribityllumazine, FMN, or riboflavin), and apparently associate with a high-energy intermediate in the luciferase reaction so that the excitation step involves a Förster-type coupling to the antenna transition, and the emission becomes that of the bound lumazine or flavin (Petushkov and Lee, 1997). It is such protein-protein interactions from the structural perspective that are the subject of the present review.

\section{Structure of bacterial luciferase}

Bacterial luciferase (PDB code 3FGC) is a heterodimer of homologous $\alpha-(\sim 40 \mathrm{kDa})$ and $\beta-(\sim 35 \mathrm{kDa})$ subunits, both of which assume the TIM $(\beta / \alpha)_{8}$ barrel fold, characteristic of the bacterial luciferase family (Fisher et al., 1995, 1996; Li et al., 2008; Campbell et al., 2009). The catalytic site resides exclusively on the $\alpha$-subunit. Binding of FMN occurs in a large open cavity accessible to solvent via an opening located at the C-terminal ends of the $\beta$-strands of the TIM-barrel structure (Fig. 1E). One wall of the cavity is lined predominantly with hydrophobic residues, while the other side is lined with charged polar residues, which places flavin in the right orientation, with the isoalloxazine ring facing the hydrophobic surface and the quininoid portion being proximal to the 

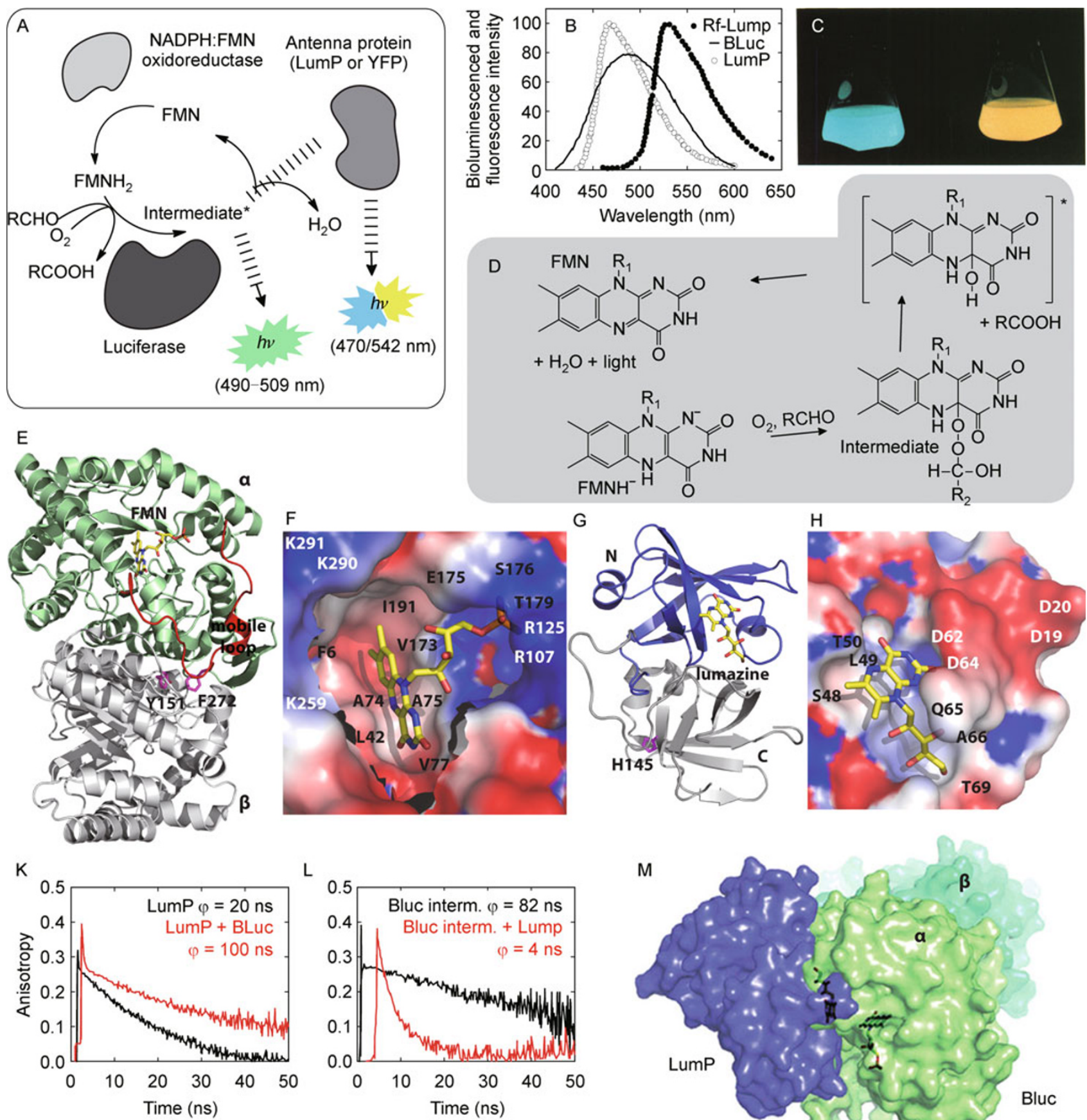

L
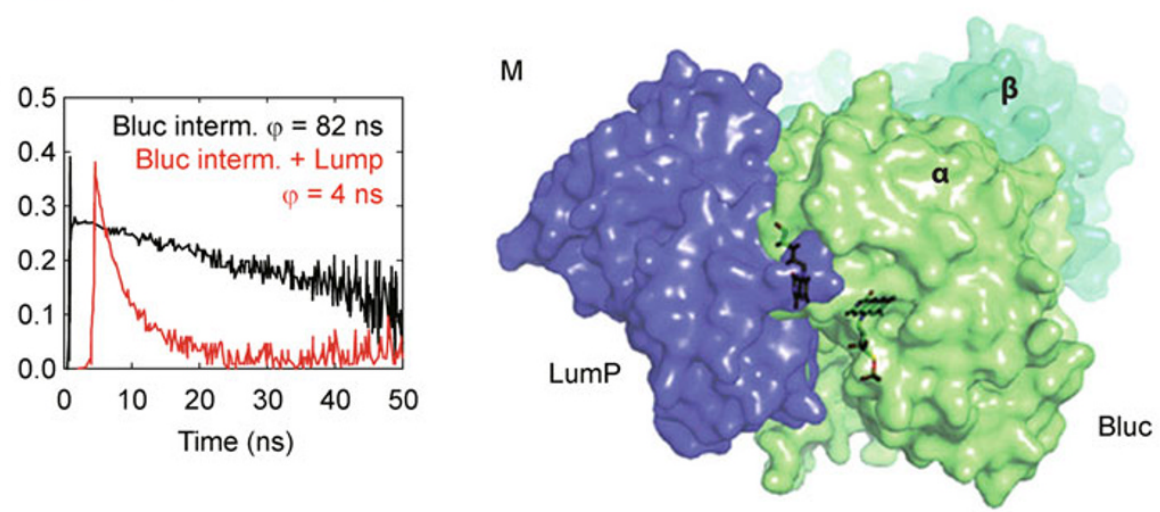

Figure 1. Bioluminescence system of bacteria. (A) Schematic representation of the bioluminescence system. (B) Bioluminescence spectra from the in vitro reaction of the bacterial luciferase alone or with addition of lumazine protein (LumP) or the riboflavin-bound LumP (Rf-LumP) to represent the spectral shift effect of antenna proteins. Shifted in vitro spectra closely resemble the in vivo bioluminescence of the bacterial species containing the corresponding antenna proteins (based on Shimomura (2006)). (C) Cultures of $P$. phosphoreum (left) and V. fischeri Y-1 (right) (from Daubner et al. (1987) reprinted with permission of use from the publisher). (D) Reaction mechanism in bacterial bioluminescence. (E) Crystal structure of bacterial luciferase (PDB code 3FGC) with $\alpha$ - and $\beta$ - subunits highlighted in different colors. (F) Part of the surface is cut to allow viewing the FMN-binding site of bacterial luciferase and the residues (in black) forming contact with FMN (yellow sticks), as well as the residues (in white) comprising the interaction surface with LumP. Electrostatic potential is shown (red for negative charge, and blue for positive charge). (G) Crystal structure of LumP (PDB code $3 \mathrm{~A} 3 \mathrm{G}$ ), with the $\mathrm{N}$ - and $\mathrm{C}$-terminal domains presented in different colors. The molecule of the lumazine derivative (yellow sticks) is shown bound to the $\mathrm{N}$-domain. $(\mathrm{H})$ Electrostatic potential surface near the lumazine-binding site (red for negative charge, and blue for positive charge). Residues coordinating the lumazine derivative are shown in black, residues of the interaction surface with luciferase are shown in white. (K) Fluorescence anisotropy of the lumazine derivative bound to LumP, and with the addition of bacterial luciferase (BLuc). (L) Fluorescence anisotropy of the luciferase-bound fluorescent transient, and with the addition of LumP. K-L are based on Lee (1993). (M) Computational structure of the bacterial lumazine-LumP complex (from Sato et al. (2010) reprinted with permission of use from the publisher). 
charged polar surface (Fig. 1F). The isoalloxazine ring of the FMN is held in place almost entirely through backbone contacts, including that with the cis-A74-A75f peptide bond of the $\beta 3$-strand important in maintaining the right conformation (Fisher et al., 1996; Campbell et al., 2009). The 5'-phosphate binding site comprises the side chains of R107, R125, E175, S176, and T179, and the backbone amide of E175 (Fig. 1F) (Campbell et al., 2009). Bacterial luciferase is an uncommon flavoprotein for it employs $\mathrm{FMNH}_{2}$ as a substrate rather than a cofactor. Oxidation of reduced flavin and long chain aldehyde by molecular oxygen provides a reaction energy of 60-80 kcal/mol (Hastings et al., 1973; Baldwin and Ziegler, 1992), sufficient to populate the excited state of a highly fluorescent luciferase-intermediate, the origin of the bioluminescence emission having a maximum around $490 \mathrm{~nm}$. The impact of the $\beta$-subunit is thought to stabilize the active form of the $\alpha$-subunit (Baldwin and Ziegler, 1992; Sinclair et al., 1993; Sparks and Baldwin, 2001; Inlow and Baldwin, 2002), and is achieved through a specific contact between the subunits involving a residue within the mobile loop (F272 on the $\alpha$-subunit and $Y 151$ on the $\beta$-subunit). This mobile loop is the most highly conserved region of the luciferase sequence, and it was suggested that it adopts discrete "open-close" conformations occurring as a slow millisecond event (Francisco et al., 1998; Campbell et al., 2009, 2010) to allow for stabilization of the high-energy intermediate. The mobile loop conformational changes might be also associated with binding of the antenna protein.

\section{Structure of lumazine protein}

The bioluminescence maximum $(470 \mathrm{~nm})$ and spectral distribution of most species of the genus Photobacterium is the same as the fluorescence of lumazine protein (LumP; $21 \mathrm{kDa}$ ) (O'Kane et al., 1985, 1991; Lee, 1993). LumP purified from extracts of these bacteria contains a noncovalently bound fluorophore, 6,7-dimethyl-8-ribityl-lumazine, or simply lumazine, the precursor of riboflavin in its biosynthesis process. If included in the in vitro bacterial luciferase reaction, LumP blue-shifts the bioluminescence from its $490-\mathrm{nm}$ maximum and also enhances the bioluminescence intensity (Fig. 1B) (O'Kane et al., 1991; Petushkov et al., 1996b). Lumazine protein (PDB code $3 A 3 G$ ) is a monomer with a spatial structure consisting of two barrels with nearly identical folds (Ca RMSD $0.90 \AA$, sequence identity $27 \%$ ). Both $\beta$-barrel domains are composed of six antiparallel $\beta$-strands and two or three small $\alpha$-helices, coinciding well with the structure of riboflavin synthase, for which the same lumazine derivative is a substrate (Fig. 1G) (Liao et al., 2001; Chatwell et al., 2008). The lumazine molecule can only bind to the $\mathrm{N}$-terminal domain of LumP, in a shallow groove comprised of residues of strands $\beta 4$ and $\beta 5$ and of helix $\alpha 2$ (Fig. $1 \mathrm{H}$ ). Binding of the lumazine in the $\mathrm{C}$-terminal domain, unlike in the synthase, is prevented by steric hindrance from H145 (Sato et al., 2010). Stabilization of the ring system and the ribityl moiety of the lumazine in the active site of LumP is achieved through a tight hydrogen bond network involving water molecules. The LumP structure is well consistent with previous biophysical studies on LumP. A polar environment of the lumazine binding site was previously suggested from the fluorescence spectral positions, fluorescence quenching, circular dichroism, and NMR data (Kulinski et al., 1987; Vervoort et al., 1990; Lee et al., 1992; Lee, 1993). Evidence suggested that the site has a high surface exposure (Lee et al., 1985) and contains no Trp, Tyr, Cys, or His residues which otherwise would quench the high quantum yield of lumazine fluorescence. Fluorescence polarization studies showed that the lumazine derivative attaches itself by burying the ribityl group into the protein, with the lumazine electronic system exposed on the surface (Lee et al., 1992).

Another antenna protein found in bioluminescent bacteria is yellow-fluorescent protein (YFP; $23 \mathrm{kDa}$ ), isolated from a unique strain Y-1, of Vibrio fischeri. YFP contains riboflavin or flavin as a fluorophore and modulates the blue bioluminescence color of the in vitro $\mathrm{Y}$-1 luciferase reaction to the yellow (maximum $542 \mathrm{~nm}$ ) (Daubner et al., 1987; Macheroux et al., 1987; Baldwin et al., 1990; Petushkov and Lee, 1997). LumP and YFP are homologous (37\%) (O'Kane et al., 1991) and also share homology with riboflavin synthase, which binds two molecules of the lumazine (O'Kane and Prasher, 1992). A remarkable property of YFP is that the bound FMN exhibits a long fluorescence lifetime (7.6 ns) and high quantum yield (0.6) commensurate with its function, as most flavoproteins are hardly fluorescent at all (Visser et al., 1997).

\section{Lumazine protein-luciferase interaction}

Addition of lumazine protein to the in vitro reaction of luciferase from Photobacterium shifts the bioluminescence emission to a shorter wavelength (maximum $470 \mathrm{~nm}$ ) in a concentration dependent manner, such as even at micromolar amounts of proteins the emission spectrum corresponds to the fluorescence of the added lumazine protein (Fig. 1B). The mechanism by which the excitation energy of the luciferase intermediate can directly populate the fluorescence state of the lumazine molecule in LumP is attributed to Förster resonance energy transfer (FRET) (Wu and Brand, 1994). For FRET to take place there must be a significant spectral overlap between the fluorescence spectrum of the donor and the absorption spectrum of the acceptor, as well as a donor-acceptor separation less than about $100 \AA$. At micromolar concentrations of luciferase and LumP (where the average distance between unassociated molecules exceeds $1000 \AA$ ), the energy transfer has to involve the formation of a LumP-luciferase complex to bring the lumazine into proximity with the luciferase reaction site (Lee et al., 1991; Lee, 1993). The existence of the YFP-luciferase complex is evidenced in an analogous manner (Petushkov et al., 1996a, 1996b).

The LumP-luciferase association is directly shown from 
dynamic fluorescence experiments. The fluorescence of LumP (maximum $475 \mathrm{~nm}$ upon excitation at $375 \mathrm{~nm}$ ) is due to the strongly bound lumazine molecule, and has a correlation time of anisotropy decay $\varphi=20 \mathrm{~ns}\left(4^{\circ} \mathrm{C}\right)$, consistent with the $21-\mathrm{kDa}$ mass of LumP. Addition of Photobacterium luciferase increases the correlation time to $\varphi=100 \mathrm{~ns}$ indicating a higher mass of the rotator $(75+$ $21 \mathrm{kDa}$ ), which in the present system corresponds to the LumP-luciferase complex (Fig. 1K). Analysis of anisotropy decay titrations suggested a $K_{D}$ in the $0.2-1 \mathrm{mmol} / \mathrm{L}$ range, an interaction much weaker than expected from the only micromolar concentrations required to affect the bioluminescence spectrum (Visser and Lee, 1982). It was proposed that a tighter interaction might be found with a luciferase reaction product such as the so-called "Fluorescent Transient," formed following the reaction of the luciferase-bound $\mathrm{FMNH}_{2}$ with $\mathrm{O}_{2}$ and aldehyde (Matheson and Lee, 1983). This fluorescent transient shows an expected $\varphi=82 \mathrm{~ns}\left(4^{\circ} \mathrm{C}\right)$ but it is reduced to $4 \mathrm{~ns}$, not increased to $100 \mathrm{~ns}$, on addition of LumP (Fig. 1L). This effect is attributed to energy transfer as a main channel of anisotropy loss concomitant with the bioluminescence spectrum matching that of the LumP fluorescence. Again, analysis of a titration based on this fluorescence anisotropy loss reveals a $K_{D}<10 \mu \mathrm{mol} / \mathrm{L}$, consistent with the micromolar concentrations required for the bioluminescence spectral shift (Lee et al., 1989, 1991; Lee, 1993). For the YFP-luciferase interaction, the rate of energy transfer was calculated as $\mathrm{k}_{\mathrm{ET}}=$ $10 \mathrm{~ns}^{-1}$ (ten times faster than with LumP $\mathrm{k}_{\mathrm{ET}} \approx 1 \mathrm{~ns}^{-1}$ ), and $\mathrm{K}_{\mathrm{D}}$ $=0.7 \mu \mathrm{mol} / \mathrm{L}$, evidence that YFP (and LumP in a less strong manner) has a catalytic effect on the luminescence reaction (Eckstein et al., 1990; Petushkov et al., 1995, 1996a, 1996b).

The spatial structure of a possible LumP-luciferase complex was derived from computational modeling using structures of bacterial luciferase with FMN (PDB code 3FGC), and LumP (PDB code 3A3G) as starting structures (Sato et al., 2010). The structure of the complex is shown in Fig. 1M. In this model structure, LumP contacts the reentrant surface of luciferase near the FMN site. The ring system of the lumazine is located close enough to the isoalloxazine ring of the FMN on the luciferase (approximately $10 \AA$ ) to allow their electronic transitions to be coupled and hence to account for moderately efficient energy transfer from the fluorescent transient to the bound lumazine. The electrostatic potentials of the molecular surfaces show that the lumazine binding site of LumP is covered by negatively charged residues (D19, D20, D62, and D64) (Fig. 1H), while the FMN site of luciferase forms a concave shape, which is surrounded by positively charged residues (R107, R125, K259, K290, and K291) (Fig. 1F). This countercharge distribution is characteristic of a variety of weak transient protein-protein complexes (Prudêncio and Ubbink, 2004; Kiel et al., 2004; Reichmann et al., 2007) and is believed to provide long-range electrostatic forces for the protein-protein interaction, which impacts on the association rate constant $\mathrm{k}_{\mathrm{A}}$ for complex formation. It is highly possible that long-range forces pre-orient LumP and luciferase molecules within an "encounter" complex, and that the successive formation of the fluorescent transient would "glue" the complex by decreasing its dissociation rate constant $k_{D}$ (Petushkov et al., 1996b; Schreiber et al., 2006). The fluorescent transient's breakdown would lead to dissociation of the complex allowing for the next turnover of luciferase with $\mathrm{FMNH}_{2}, \mathrm{O}_{2}$ and aldehyde. It also has to be emphasized, that a luciferase complex must be formed prior to the actual bioluminescence excitation step so that the LumP is available to trap the energy before it is emitted at the longer wavelength (energy transfer rate $\mathrm{k}_{\mathrm{ET}} \approx 1 \mathrm{~ns}^{-1}$ ) (Visser and Lee, 1982; Lee et al., 1991).

\section{JELLYFISH CLYTIA}

C. gregaria is a pelagic hydrozoan jellyfish commonly found in the eastern Pacific Ocean (Fig. 2C). Its green bioluminescence (maximum $509 \mathrm{~nm}$ ), thought to have a defensive function, is emitted upon mechanical stimulation from light organs (photophores) distributed evenly along the edge of the umbrella, and containing the photoprotein clytin and its cognate green-fluorescent protein (Clytia GFP). Clytia utilizes coelenterazine, the most widely found luciferin among marine animals, as a substrate for its bioluminescence reaction. Like the photoprotein aequorin from the jellyfish Aequorea victoria, clytin is a $\mathrm{Ca}^{2+}$-regulating photoprotein, and tightly binds and stabilizes a hydroperoxy-substituted coelenterazine within an inner cavity. Binding of $\mathrm{Ca}^{2+}$ to these photoproteins triggers the bioluminescence reaction to produce the excited state product coelenteramide and $\mathrm{CO}_{2}$ (Fig. 2A). In the GFP-clytin complex, this excitation step involves again a Förster-type transition coupling with the green fluorescence of the Clytia GFP's fluorophore (maximum $500 \mathrm{~nm}$ ). With no Clytia GFP presence, the bioluminescence emission has a maximum around $470 \mathrm{~nm}$ (Fig. 2B) (Levine and Ward, 1982; Inouye and Tsuji, 1993; Markova et al., 2010). That these photoproteins are activated or regulated by $\mathrm{Ca}^{2+}$ implies that the bioluminescence system is under control of the neural system of the animal (Dunlap et al., 1987).

\section{Structure of the photoprotein clytin}

Clytin (22.4 kDa, PDB code 3KPX) shares high structural and sequence similarity with the other $\mathrm{Ca}^{2+}$-regulated photoproteins, obelin from Obelia (Liu et al., 2000) and aequorin from Aequorea (Head et al., 2000). Photoproteins can be regarded as a luciferase except with its high-energy reaction intermediate, 2-hydroperoxycoelenterazine, frozen in place (Hastings and Gibson, 1963). The spatial structure of the protein contains four helix-turn-helix motives known as EF-hands, wrapped to form a two-bowls like globular structure. This 

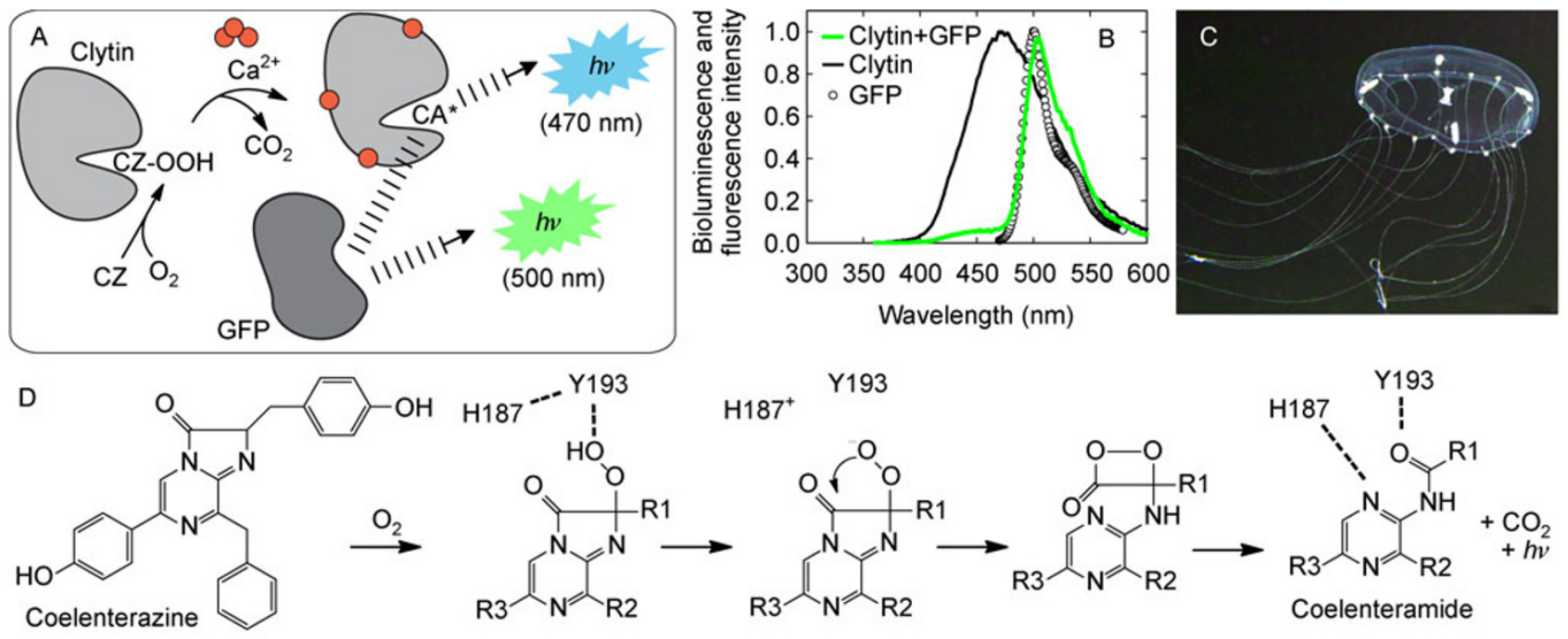

(187
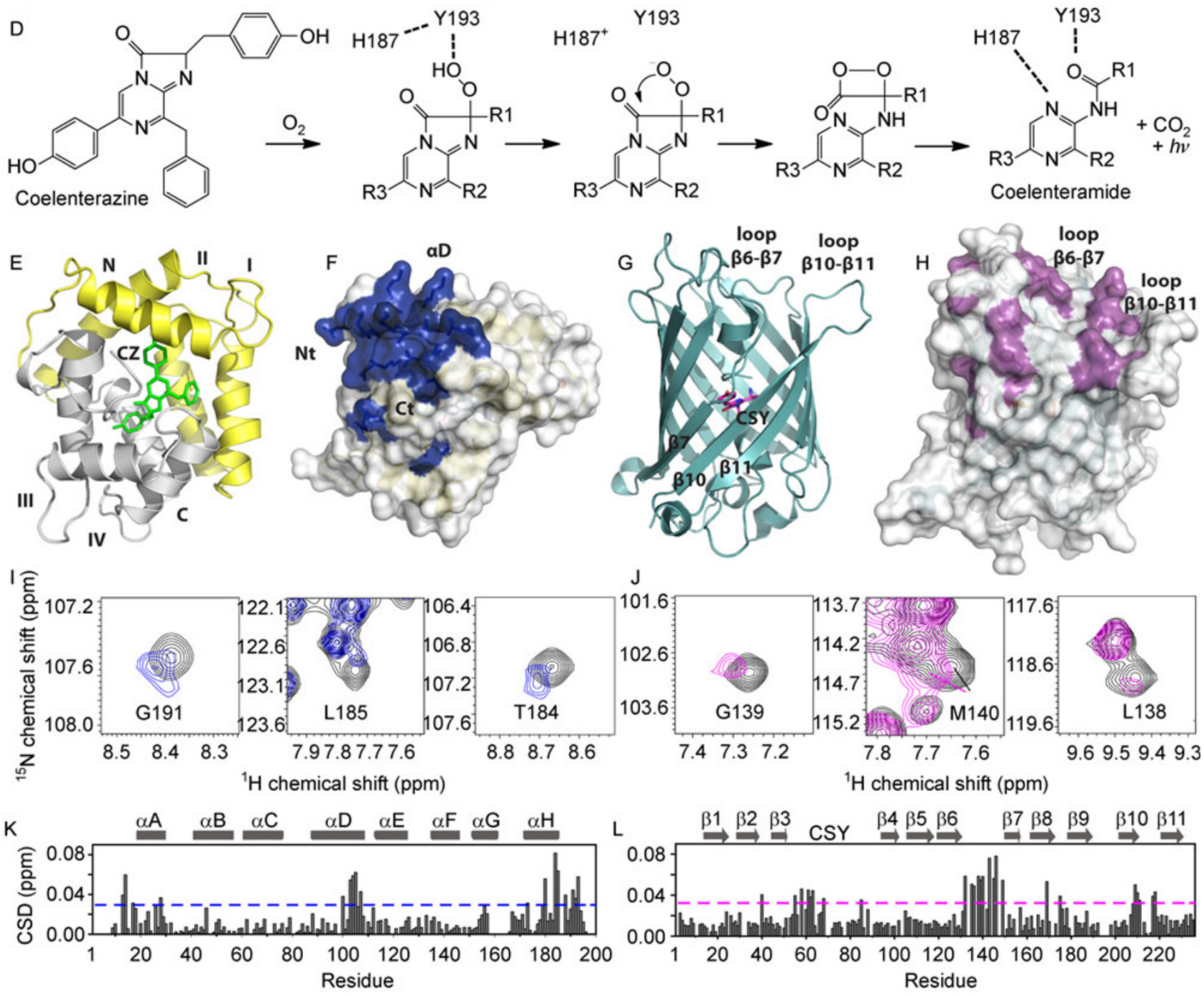

Figure 2. Bioluminescence system of the jellyfish Clytia. (A) Schematic representation of the bioluminescence system of the $\mathrm{Ca}^{2+}$-regulated photoproteins. Clytin is from the jellyfish Clytia. $(\mathrm{CZ}=$ coelenterazine, $\mathrm{CA}=$ coelenteramide, Fig. $2 \mathrm{D})$. $(\mathrm{B})$ Bioluminescence spectra of clytin, and clytin with Clytia GFP, to demonstrate the spectral shift due to energy transfer. The Clytia GFP fluorescence is in green (based on Titushin et al. (2010)). (C) Photograph of Clytia hemisphaerica (courtesy of Tsuyoshi Momose). (D) Chemical mechanism of photoprotein bioluminescence. Key binding site residues of clytin are shown in bold (based on Vysotski and Lee (2007)). (E) Spatial structure of the photoprotein clytin (CZ = green sticks) with N- and C- terminal domains represented by different colors. $\mathrm{Ca}^{2+}$-binding loops are numbered. (F) Interaction surface of clytin with Clytia GFP derived from NMR-titration experiments. Shown in blue are the residues experiencing chemical shift difference (CSD) larger than one standard deviation. (G) Crystal structure of Clytia GFP with labeled $\beta$-strands $\beta 6, \beta 10, \beta 11$ and corresponding loops involved in the interaction with clytin. $(\mathrm{H})$ Interaction surface of Clytia GFP with clytin derived from NMR-titration experiments. Shown in magenta are the residues experiencing CSD larger than one standard deviation. (I and J) ${ }^{1} \mathrm{H}-{ }^{15} \mathrm{~N} H S Q C$ spectral areas superposed from the ${ }^{15} \mathrm{~N}$ labeled clytin (I, black) and ${ }^{15} \mathrm{~N},{ }^{2} \mathrm{H}$-labeled Clytia GFP (J, black) with unlabeled Clytia GFP (blue) and clytin (magenta), respectively. ( $K$ and L) Weighted-average CSD between ${ }^{15} \mathrm{~N}$-clytin $(\mathrm{K})$ or ${ }^{15} \mathrm{~N},{ }^{2} \mathrm{H}$-Clytia GFP $(\mathrm{L})$ and $1: 3{ }^{15} \mathrm{~N}$-clytin/Clytia GFP and $1: 2{ }^{15} \mathrm{~N},{ }^{2} \mathrm{H}$ Clytia GFP/clytin mixtures. The dashed lines represent the one standard deviation cut-off. Secondary structure elements are shown. $\mathrm{E}-\mathrm{L}$ are from Titushin et al. (2010) reprinted with permission of use from the publisher. 
structure protects and stabilizes the 2-hydroperoxycoelenterazine, and allows binding of $\mathrm{Ca}^{2+}$ to trigger the bioluminescence reaction. EF-hands I and II are in the Nterminal, and III and IV are in the C-terminal (Fig. 2E). Only three EF-hands I, III, and IV bind calcium, while EF-hand II lacks the canonical sequence in the loop to permit calcium binding (Deng et al., 2005; Vysotski and Lee, 2007). The hydrophobic substrate-binding cavity is comprised of highly conserved residues from almost every a-helix (A-H). Tryptophans W95, W182, W117, and W138 form a "sandwich" structure to orient the 2-hydroperoxycoelenterazine. Residues Y193 and $\mathrm{H} 178$ form a hydrogen bond network holding the highly unstable peroxy group of 2-hydroperoxycoelenterazine. The mechanism of the bioluminescence reaction involves conformational changes of clytin upon binding of $\mathrm{Ca}^{2+}$ in the EF-hand loops. This disturbs the hydrogen bond network around the peroxy group, which in turn triggers decarboxylation of the 2-hydroperoxycoelenterazine, ending up in formation of the product excited coelenteramide and emission of blue light (Fig. 2D) (Head et al., 2000; Liu et al., 2006). Clytin completes only one turnover in vitro because after the bioluminescence reaction the product remains tightly bound.

\section{Structure of Clytia GFP}

Clytia GFP from $C$. gregaria (PDB code 2HPW) forms the classical $\beta$-barrel structure $(30 \times 40 \AA)$ characteristic of this family of fluorescent proteins. Despite a low sequence identity, the structure of Clytia GFP highly resembles GFPs from Aequorea (Ormö et al., 1996) and Renilla (Loening et al., 2007). Eleven parallel $\beta$-strands (S1-S11) comprise the "walls" of the barrel, and loops cover the barrel from the "top" and "bottom" blocking solvent access to the internal cavity (Fig. 2G). The chromophore of Clytia GFP, 5-(phydroxybenzylidene)imidazolin-4-one, is a product of posttranslational autocatalytic cyclization of S68, Y69, and G70 amino acid residues (Remington, 2006; Wachter, 2007). Covalently attached to the core a-helix, the fluorophore resides in the center of the protein cylinder in a polar environment, very well protected from the solvent. This apparently minimizes energy dissipation upon fluorescence excitation to favor a high quantum yield of the Clytia GFP fluorescence (0.86; maximum $500 \mathrm{~nm}$ upon excitation at $470 \mathrm{~nm}$ ) (Markova et al., 2010). From analytical ultracentrifugation, size-exclusion chromatography and fluorescence anisotropy data, Clytia GFP is an obligate dimer (Titushin et al., 2010; Malikova et al., 2011). The dimerization interface of the Clytia GFP monomer reveals hydrogen bonding and an accessible surface area value $\left(1370 \AA^{2}\right)$ favorable for strong dimerization (Jones and Thornton, 1996). Within the dimer, the two fluorophores have a coupled electronic state transition (Malikova et al., 2011).

\section{Clytia GFP-clytin interaction}

Isolated clytin converts 2-hydroperoxycoelenterazine into coelenteramide with emission of a broad blue bioluminescence (maximum $470 \mathrm{~nm}$ ). Upon titration with Clytia GFP, a second longer wavelength band appears and at only micromolar concentrations of both proteins, the bioluminescence (maximum $497 \mathrm{~nm}$ ) becomes identical to that of the Clytia GFP fluorescence (Fig. 2B). As in the case of bacterial luciferase and lumazine protein, the energy transfer in the Clytia GFP-clytin system is rationalized by the FRET mechanism. The requirement of donor-acceptor separation to be less than $100 \AA$ at micromolar concentrations of clytin and Clytia GFP can only be achieved assuming a tight protein-protein interaction (Förster, 1960; Wu and Brand, 1994; Titushin et al., 2010; Markova et al., 2010). Although the bioluminescence spectrum shift is complete at micromolar amounts of proteins, implying $\mathrm{K}_{\mathrm{D}}$ of Clytia GFP-clytin complexation to be in the micromolar range, no evidence for protein-protein association could be found from analytical ultracentrifugation, size-exclusion chromatography, surfaceplasmon resonance, or polarization fluorometry experiments, which are capable of detecting complexation with a $\mathrm{K}_{\mathrm{D}}$ below $10^{-4} \mathrm{~mol} / \mathrm{L}$ (Titushin et al., 2010; Malikova et al., 2011).

However, a weak complex could be detected with NMR chemical shift perturbation mapping, a technique that is capable of measuring weak protein-protein interactions up to $\mathrm{K}_{\mathrm{D}}=10^{-2} \mathrm{~mol} / \mathrm{L}$, owing to the remarkable sensitivity of ${ }^{15} \mathrm{~N}-{ }^{-1} \mathrm{H}$ HSQC chemical shifts to subtle conformational effects (Zuiderweg, 2002; Vaynberg and Qin, 2006). When an ${ }^{15} \mathrm{~N}$ labeled clytin sample is titrated with unlabeled Clytia GFP, about 15 peaks on the ${ }^{15} \mathrm{~N}-{ }^{1} \mathrm{H}$ HSQC spectrum of clytin experience concentration dependent chemical shift perturbation assignable to interaction with Clytia GFP (Fig. 2l and 2K). Analogously, the ${ }^{15} \mathrm{~N}-{ }^{1} \mathrm{H}$ HSQC spectrum of ${ }^{15} \mathrm{~N}$-labeled Clytia GFP reveals approximately 20 peaks with chemical shift altered upon titration with unlabeled clytin (Fig. $2 \mathrm{~J}$ and $2 \mathrm{~L}$ ). The perturbed shifts are small in amount and also exist in the fast chemical exchange regime on the NMR-time scale; therefore no significant conformational changes of the proteins occur upon the interaction. Subsequent to assignment of the HSQC spectra, the perturbed peaks could be attributed to certain amino acid residues of both clytin and Clytia GFP, and accordingly, located on their 3-D spatial structures as belonging to the interaction surfaces of the proteins.

NMR chemical shift perturbation mapping indicated a continuous path on the clytin surface involving the aminoterminus, $\alpha$-helix $D$, and the carboxy-terminus, which are contiguous in the spatial structure (Fig. 2F). Residues of Clytia GFP under "perturbation" clustered on loops S6-S7 and S10-S11, comprising the "top" of the Clytia GFP barrel (Fig. 2H). The crystal structures of clytin and Clytia GFP 

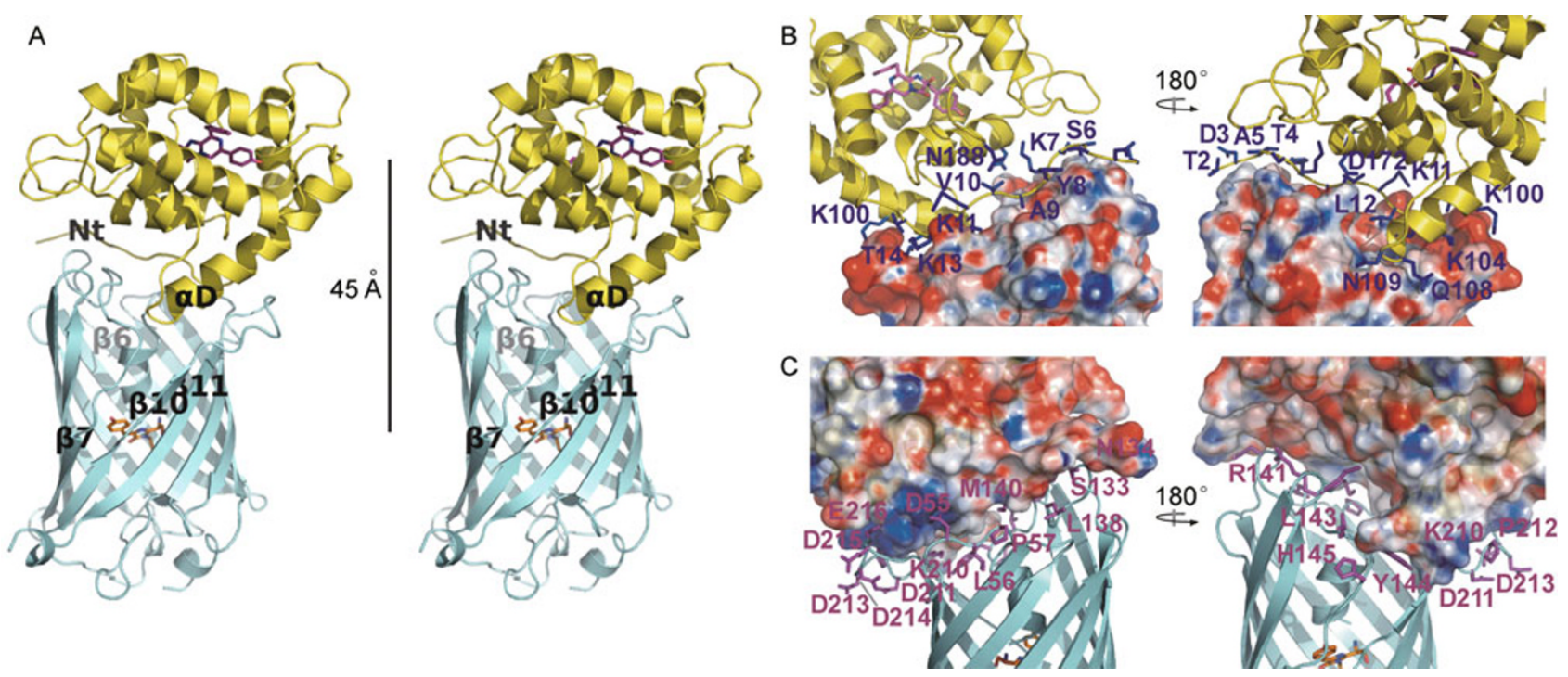

Figure 3. Spatial structure of the Clytia GFP-clytin complex (from Titushin et al. ( 2010)). (A) Stereoview representation of the Clytia GFP-clytin complex derived from crystal structures of clytin and Clytia GFP, NMR-mapping of the interaction surfaces and computational docking in HADDOCK. $45 \AA$ is the distance between the two chromophores. Structural elements of clytin and Clytia GFP comprising the interaction surface are labeled. (B and C) The Clytia GFP-clytin interface. Two sides of the molecules are rotated by $180^{\circ}$ to allow for viewing of the interaction surfaces. The electrostatic surface of Clytia GFP (B) and clytin (B) are shown. PoissonBoltzmann electrostatics calculations were done within PDB2PQR (Dolinsky et al., 2004) and evaluated in APBS (Baker et al., 2001). The positively charged, negatively charged, and neutral amino acid residues are represented in blue, red, and white, respectively. Residues of clytin (B) and of Clytia GFP (C) buried in the contact surface are shown as blue and magenta sticks, respectively.

along with the above designated interaction surfaces were the basis for computing the spatial structure of the Clytia GFPclytin complex by means of modeling using the "soft-docking" program HADDOCK2.0 (Dominguez et al., 2003; de Vries et al., 2007). The resulting lowest energy structure is shown in Fig. 3A. This Clytia GFP-clytin structure bears the characteristics of a weak protein-protein complex, with a relatively small number of intermolecular contacts, an average interaction surface area (Lo Conte et al., 1999), and a notable charge complementarity of the interfaces. Basic amino acid residues (K11, K13, K100, and K104) introduce positive charge into the interface of clytin, and complementarity to it (also in shape) lies in the acidic loop S10-S11 of Clytia GFP, comprised of residues D211, D213, D214, D215, and E216 (Fig. 3B and 3C). Apart from electrostatic forces, the complexation is governed by a number of hydrophobic contacts and a hydrogen bond network. The fluorophores of clytin and Clytia GFP lie $45 \AA$ apart which, together with the very favorable spectral overlap of clytin bioluminescence and Clytia GFP absorbance $\left(\mathrm{J}=1.3 \times 10^{-13} \mathrm{~L} \cdot \mathrm{mol}^{-1} \cdot \mathrm{cm}^{-3}\right)$, would account for efficient energy transfer from the excited state coelenteramide to the fluorophore of Clytia GFP. Each monomer of the Clytia GFP homodimer can accommodate one molecule of clytin, which would argue for a tetrameric complex of 2 clytins per Clytia GFP (dimer). The supposition of a heterotetrameric complex was advanced for in vivo aequorin-Aequorea GFP (Cutler and Ward, 1997).
Both clytin and $\mathrm{Ca}^{2+}$-loaded clytin (that is "before" and "after" the bioluminescence reaction) interact only weakly with Clytia GFP as observed from NMR titration, polarization and dynamic fluorescence, and isothermal titration calorimetry experiments $\left(\mathrm{K}_{\mathrm{D}}, \sim 0.9 \mathrm{mmol} / \mathrm{L}\right)$, whereas the bioluminescence effect of Clytia GFP is complete at micromolar concentrations of proteins. To rationalize this contradiction it was hypothesized that on triggering by binding $\mathrm{Ca}^{2+}$, clytin adopts an intermediate conformation state regarded as a "pre-excited state" clytin, in which its affinity to Clytia GFP is enhanced several orders of magnitude. Within this short lived complex, the chemiexcitation step occurs to populate the coelenteramide-GFP coupled electronic state, resulting in an $\mathrm{S}_{1} \rightarrow \mathrm{S}_{0}$ radiative transition corresponding to the fluorescence of the acceptor, Clytia GFP. This proposal bears similarity to the bacterial lumazine protein-luciferase interaction discussed above, and the property of the energized intermediate of the luciferase reaction in enhancing the lumazine proteinluciferase interaction (Petushkov et al., 1996a). Hence, the structure of the Clytia GFP-clytin complex derived from NMR mapping very probably only represents the structure of the encounter complex of low affinity, in which clytin (of the "before" luminescence reaction state) and Clytia GFP are preoriented, and then this is followed by formation of the preexcited state complex. lonic strength sensitivity of the Clytia GFP-clytin interaction confirms the significant role of electrostatic forces known to be an attribute of an encounter complex 
(Berg and von Hippel, 1985; Sheinerman et al., 2000; Schreiber et al., 2006). Supporting the validity of the Clytia GFP-clytin structure were mutational experiments indicating that substitutions of the residues on the clytin interface decrease both the complex affinity and the energy transfer efficiency, with substitutions disturbing polar contacts having the largest effect.

\section{SOFT CORAL RENILLA}

The sea pansy Renilla found in shallow sandy littoral bottoms emits bright green bioluminescence (maximum $505 \mathrm{~nm}$ ) probably as a defensive reaction to mechanical disturbance, putatively to deter predators from nibbling at the polyps (Fig. 4C) (Cormier et al., 1974, 1975). The bioluminescence originates from single polyps, wherein the system is packaged in specialized light emitting cells (photocytes) that contain luciferase, Renilla GFP, and the substrate coelenterazine bound to the $\mathrm{Ca}^{2+}$-triggered coelenterazine-binding protein (CBP) (Fig. 4A) (Anderson and Cormier, 1973; Cormier and Charbonneau, 1977; Cormier, 1978; Charbonneau and Cormier, 1979). When the $\mathrm{Ca}^{2+}$ concentration rises upon nerve stimulation, $\mathrm{Ca}^{2+}$ binds to $\mathrm{CBP}$ to make coelenterazine available for reaction with luciferase and $\mathrm{O}_{2}$. It is proposed that the bioluminescence reaction occurs within a CBP-luciferase complex so that coelenterazine does not necessarily dissociate (Charbonneau and Cormier, 1979; Titushin et al., 2008; Stepanyuk et al., 2009). Following oxygen addition to coelenterazine in the active site of luciferase, the decarboxylation reaction deposits excitation again into the coupled electronic state transitions of the coelenteramide-GFP fluorophore pair, from which $S_{1} \rightarrow S_{0}$ radiation as GFP's green fluorescence takes place $(509 \mathrm{~nm})$. In the absence of GFP the light is blue $(480 \mathrm{~nm})$ (Fig. 4B) (DeLuca et al., 1971; Hart et al., 1979; Shimomura, 2006). To enable the energy transfer, Renilla luciferase and Renilla GFP are required to form a protein-protein complex (Ward and Cormier, 1976, 1978; Ward, 1979), and so luciferase must interact simultaneously with both proteins, CBP and GFP. Despite solid biophysical data on Renilla GFP-Renilla luciferase complexation, no structural information is available for this interaction at the present time.

\section{Structure of Renilla luciferase}

Renilla luciferase ( $37 \mathrm{kDa}, \mathrm{PDB}$ code $2 \mathrm{PSJ}$ ) is a monomeric protein, which catalyzes the decarboxylation of coelenterazine in the presence of molecular oxygen, resulting in the product coelenteramide, carbon dioxide, and blue light (maximum $480 \mathrm{~nm}$ ) (Karkhanis and Cormier, 1971; Matthews et al., 1977a, 1977b; Lorenz et al., 1991). The crystal structure was solved for the stabilized mutant form of luciferase from $R$. reniformis and is shown in Fig. 4F. It has a characteristic $\alpha / \beta$-hydrolase fold sequence at its core, that is an $\alpha / \beta$-sheet of eight $\beta$-sheets connected by $\alpha$-helices (Ollis et al., 1992), and shares the conserved catalytic triad of residues D120/E144/H285A employed by the dehalogenases, with $D 120$ being a part of a characteristic "nucleophile elbow." (Holmquist, 2000; Loening et al., 2006) However, in Renilla luciferase this triad is employed in an oxidation reaction, while in dehalogenase it catalyzes a hydrolysis reaction, which makes a high level of primary sequence and tertiary structure similarity between them very intriguing (Loening et al., 2007). This triad and residues N53/ W121/P220 comprise the catalytic core clustered toward the bottom of the bowl-shaped active site. Enzymatic assay, mutagenesis data, and docking computation reveal that catalytic triad D120/E144/H285A is directly involved in the decarboxylation reaction of coelenterazine, apparently coordinating the attack of the coelenterazine molecule by molecular oxygen (Woo et al., 2008). Around this core is a ring of aromatic residues, which assure specificity of binding and right orientation of the hydrophobic coelenterazine. The bioluminescence reaction of Renilla luciferase is dependent upon the flexible cap domain, which is thought to assist binding of coelenterazine, and may also be responsible for an immediate relocation of the product coelenteramide in the active site after the enzymatic reaction (Loening et al., 2007).

\section{Structure of coelenterazine-binding protein (CBP)}

Coelenterazine-binding protein is a $\mathrm{Ca}^{2+}$-regulated protein (21 kDa, PDB code 2HPS), containing coelenterazine bound within its inner cavity (Charbonneau and Cormier, 1979; Kumar et al., 1990; Inouye, 2007; Stepanyuk et al., 2009). Despite low sequence identity, the structure of CBP closely resembles structures of photoproteins obelin, aequorin and clytin. Four sets of helix-turn-helix structural motives, which are characteristic of EF-hand calcium-binding domains, comprise again two "bowls" folded over the coelenterazine molecule (Fig. 4H). Unlike in photoproteins, coelenterazine in CBP is found unsubstituted, without the peroxy group. This is consistent with their difference in function, i.e. CBP does not catalyze oxidation of coelenterazine, but rather undergoes conformational changes triggered by binding of calcium, resulting in release of coelenterazine for oxidation and decarboxylation in the active center of luciferase (Stepanyuk et al., 2009). In this regard, a photoprotein can be thought of having the combined functions as a substrate binding protein and as a luciferase, with a $\mathrm{Ca}^{2+}$-sensitive link to a neural network. The CBP holding coelenterazine also protects it from autooxidation and rapid diffusion otherwise allowed by the hydrophobic nature of the molecule (Shimomura, 1997). Compared to photoproteins, the substrate-binding cavity of CBP is more hydrophilic, contains no tryptophan residues, and coordinates coelenterazine by hydrogen bonding with residues $\mathrm{Y} 36, \mathrm{R} 22, \mathrm{R} 19, \mathrm{~K} 139, \mathrm{D} 183$, and five water molecules, which altogether account for weaker affinity of 


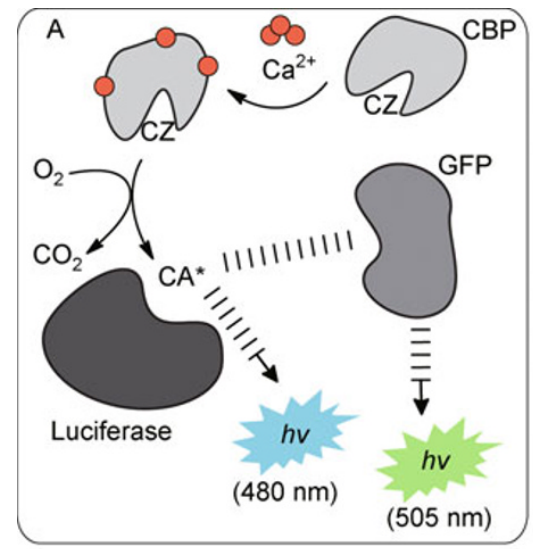

$\mathrm{F}$

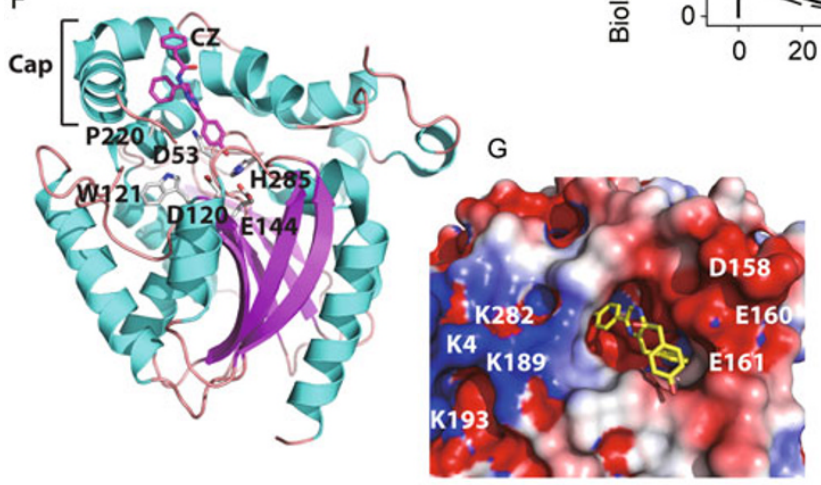

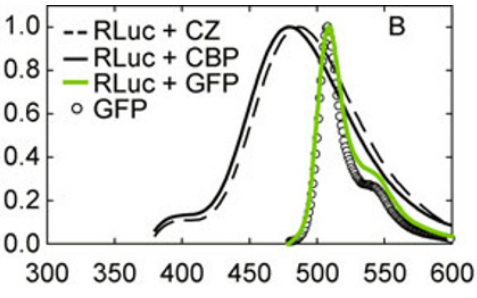

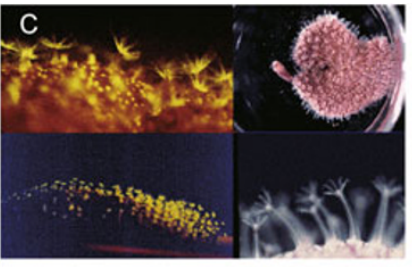

Wavelength $(\mathrm{nm})$

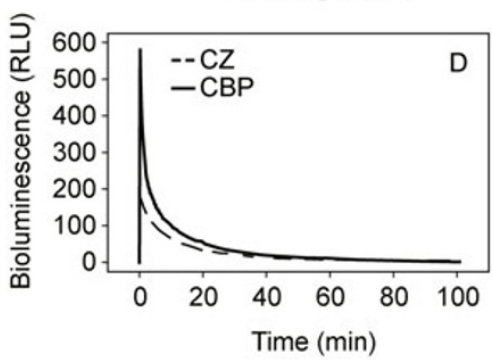

$\mathrm{H}$

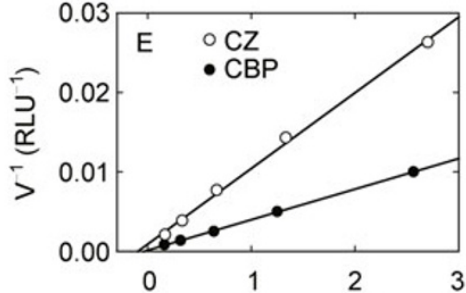

$[\mathrm{CBP}]^{-1}$ or $\left.[\text { Coelenterazine }]^{-1}\left[(\mu \mathrm{mol} / \mathrm{L})^{-1}\right)\right]$

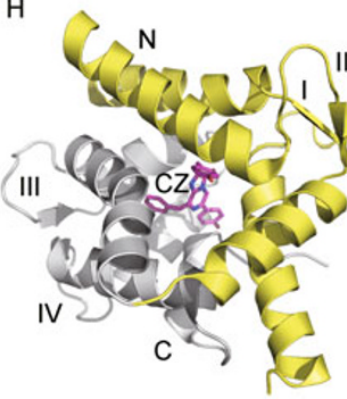

I

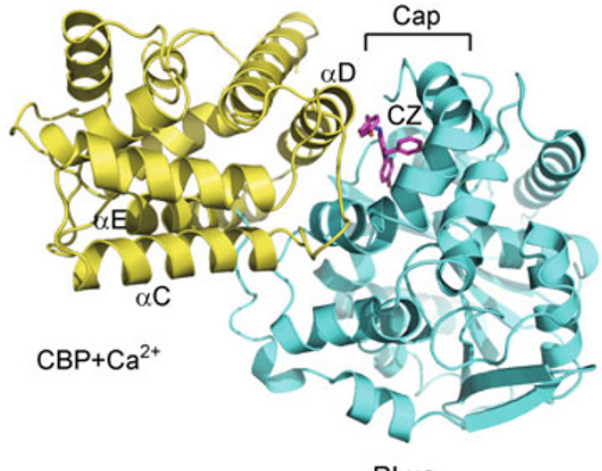

RLuc
K
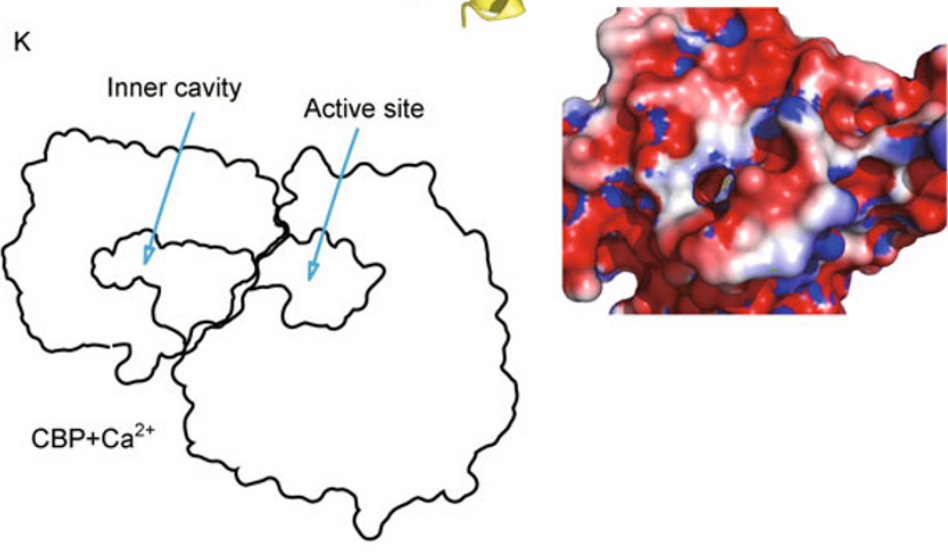

RLuc

Figure 4. Bioluminescence system of Renilla. (A) Schematic representation of the bioluminescence system. (B) Bioluminescence spectra of the luciferase reaction with coelenterazine $(\mathrm{CZ})$ and $\mathrm{CBP}$, and with addition of micromolar amounts of Renilla GFP to demonstrate the spectral shift due to energy transfer. The native Renilla GFP fluorescence is in green (based on Titushin et al. (2008)). (C) Photograph of the soft coral Renilla (source http://cochin.inserm.fr/la_recherche/departements/emc/ equipe-jockers/techniques). (D) Bioluminescent signal records for luciferase from $R$. muelleri with $\mathrm{CZ}$ and $\mathrm{CBP}$ at equal concentrations. The light yield with $\mathrm{CZ}$ is $50 \%$ that with $\mathrm{CBP}$. (E) Lineweaver-Burk plot of CBP and coelenterazine. The concentrations of $C B P$ and $C Z$ are at $\mu \mathrm{mol} / \mathrm{L}$. RLU = initial bioluminescence intensity in relative light units. Apparent $\mathrm{k}_{\text {cat }} / \mathrm{K}_{\mathrm{m}}$ with $\mathrm{CZ}$ is $57 / \mathrm{L} \cdot \mu \mathrm{mol}^{-1} \cdot \mathrm{s}^{-1}$, and with CBP $136 / \mathrm{L} \cdot \mu \mathrm{mol}^{-1} \cdot \mathrm{s}^{-1}$, demonstrating more than 2 times higher efficiency of luciferase with CBP than with free CZ. D-E are from Titushin et al. (2008). (F) Crystal structure of Renilla luciferase mutant (PDB code 2PSJ). Structural elements are defined in different colors. Residues involved in catalytic reaction with coelenterazine are shown as sticks and labeled. (G) Electrostatic potential surface surrounding the active site of luciferase. Residues comprising the interaction surface with $\mathrm{Ca}^{2+}$-loaded CBP are in white. $(\mathrm{H})$ Crystal structure of CBP (PDB code 2HPS) with $\mathrm{N}$ - and C-terminal domains shown in different colors. $\mathrm{Ca}^{2+}$-binding loops are numbered. (I) Surface representation of $\mathrm{CBP}$ (lower) and $\mathrm{Ca}^{2+}$-loaded $\mathrm{CBP}$ (upper) to demonstrate the opened aperture on the surface of $\mathrm{Ca}^{2+}$-loaded CBP (PDB code 2HQ8). Residues comprising the interaction surface with luciferase are in white. $(\mathrm{J})$ Computational structure of the $\mathrm{Ca}^{2+}$-loaded CBP-luciferase complex. Labeled are the $\alpha$ helices $\mathrm{C}, \mathrm{D}$, and $\mathrm{E}$ of $\mathrm{Ca}^{2+}$-loaded CBP forming the newly opened aperture. Cap domain and coelenterazine-binding site of luciferase are labeled. $(\mathrm{K})$ Cartoon representation of the complex to show the coelenterazine-binding cavity of $\mathrm{Ca}^{2+}$-loaded CBP aligned towards the active site of Renilla luciferase. 
coelenterazine to the binding cavity. Availability of spatial structures of $\mathrm{CBP}$ and apo-CBP loaded with $\mathrm{Ca}^{2+}$ reveals that binding of $\mathrm{Ca}^{2+}$ to three EF-hand loops of CBP stretches their conformation, so that helices $\mathrm{C}, \mathrm{D}$, and $\mathrm{E}$ are moved apart to close a small aperture on the protein surface, and a new and bigger one opens on the opposite side (Fig. 4I). Displacement of the cavity comprising residues "pushes out" the coelenterazine to the newly opened aperture, which would look like a perfect gate for coelenterazine to escape, for it is no longer tightly bound in the cavity due to the loss of the original contacts after shift of the hydrophobic side chains (Phe, Met, Val, and Leu), and because the R19 "lid" becomes opened up (Stepanyuk et al., 2009).

\section{CBP-Renilla luciferase interaction}

Indirect evidence for this CBP-luciferase association is derived from kinetic characteristics of the in vitro luciferase reaction. The bioluminescence reaction of Renilla luciferase is triggered either by injection of coelenterazine into a solution of luciferase, or by injection of calcium into a mixture of luciferase and CBP (Matthews et al., 1977a; Titushin et al., 2008). Both reactions have very similar bioluminescence spectra (Fig. 4B), implying that the chemical mechanism of the reaction and structure of the bioluminescence emitter must be identical. However, kinetic parameters of the reactions are different, such as luciferase is able to turn over with coelenterazine enclosed within CBP six times faster than with free coelenterazine, and emits with a two-fold higher quantum yield (Fig. 4D and 4E) (Titushin et al., 2008). Knowing that apo-CBP does not enhance luciferase activity, a higher bioluminescence quantum yield for Renilla luciferase with CBP as its substrate, would be difficult to explain if coelenterazine had to first dissociate from $\mathrm{Ca}^{2+}$-loaded CBP into solution. The absorbance spectra of $\mathrm{CBP}, \mathrm{Ca}^{2+}$-loaded $\mathrm{CBP}$, and an aqueous solution of coelenterazine, differ in the position of the visible maximum $(444 \mathrm{~nm}, 434 \mathrm{~nm}$, and $415 \mathrm{~nm}$ respectively), revealing that for these three cases, the chemical environment of the coelenterazine molecule must be different. Besides, $\mathrm{Ca}^{2+}$-loaded CBP is weakly fluorescent, while an aqueous solution of coelenterazine is non-fluorescent (Shimomura and Teranishi, 2000), which altogether implies that coelenterazine does not necessarily dissociate, but rather stays bound, at least for several minutes, within the cavity of $\mathrm{Ca}^{2+}$-loaded CBP. Then for the bioluminescence reaction to proceed, coelenterazine should be delivered to the active center of luciferase within a transient protein-protein complex, which dissociation should be rapid enough to allow the luciferase turnover to be $2-5 \mathrm{~s}^{-1}$ (Hart et al., 1979; Loening et al., 2006). The characteristic for such a transient complex is usually an electrostatic complementarity of interaction surfaces of proteins (Prudêncio and Ubbink, 2004; Kiel et al., 2004; Reichmann et al., 2007). This complementarity is observed between the path around the active site of luciferase and the path around the aperture of
$\mathrm{Ca}^{2+}$-loaded CBP (Fig. 4G and 4I). Apart from this complementarity, the 2-( $p$-hydroxybenzyl) group of coelenterazine, the region of oxygen attack catalyzed by luciferase, also becomes exposed through the newly opened aperture of the $\mathrm{Ca}^{2+}$-loaded CBP.

To obtain the spatial structure of the $\mathrm{Ca}^{2+}$-loaded CBPluciferase complex, a docking simulation was performed using structures of the luciferase from $R$. muelleri modeled in SWISS-MODEL (Arnold et al., 2006) on the highly homologous structure of the luciferase from $R$. reniformis (PDB code $2 \mathrm{PHW}$ ), and the structure of $\mathrm{Ca}^{2+}$-loaded CBP of $R$. muelleri (PDB code 2HQ8). Both an interaction-restraints driving docking (HADDOCK2.0) and an ab initio docking software (PatchDoc) (Schneidman-Duhovny et al., 2005) resulted in lowest energy structures with very similar topology (Stepanyuk et al., 2009; Titushin, 2009). On these structures, as well as on the best energy score structure shown in Fig. $4 \mathrm{~J}$, the opening on the surface of the $\mathrm{Ca}^{2+}$-loaded CBP structure interacts with good shape complementarity, with the path flanking the active site of luciferase. On the interface of $\mathrm{Ca}^{2+}$ loaded CBP, residues R9, K91, K93, K97, and D66, E80, D87 interact complementarily in charge, with corresponding residues D158, E160, E161, and K4, K189, K193, K282 of luciferase (Fig. $4 \mathrm{G}$ and $4 \mathrm{I}$ ). The number of hydrogen bonds and intermolecular contacts imply a weak interaction with a moderate size interaction surface area $\left(\sim 1800 \AA^{2}\right)$. There is a path observed in the structure, which might serve as a route for coelenterazine to relocate from the substrate-binding cavity of $\mathrm{Ca}^{2+}$-loaded CBP towards the active site of luciferase to undergo the catalytic oxidation and decarboxylation (Fig. 4K). The resulting product of the reaction, excited state coelenteramide, may be regarded as partly protected from the solution by the protein-protein complex environment, and is thus subjected to a lesser energy dissipation, which would explain the higher quantum yield of the reaction of luciferase with $\mathrm{CBP}$ rather than with free coelenterazine. It should be noted that the spatial structure of the complex needs more verification, and more attempts should be tried to apply NMR-mapping and X-ray crystallography if we are to have a more substantial understanding of the mechanism of Renilla bioluminescence.

\section{CONCLUDING REMARKS}

It has been suggested that coelenterazine may have a role in the metabolism of marine creatures other than as a substrate for bioluminescence (Shimomura, 2006; Haddock et al., 2010). If this is the case, then it would be another example like 6,7-dimethyl-8-ribityllumazine (lumazine), of a metabolite being seconded in the process of evolution, to perform a novel function. The chemistry of the light reaction limits the natural bioluminescence spectra to maxima in the range $465-495 \mathrm{~nm}$, but the presence of the GFPs extends this to slightly longer wavelengths, apparently to better suit the photic environment closer to surface regions. In the biolumi- 
nescent bacteria, the antenna proteins LumP and YFP also alter the color of bioluminescence over about the same range, but additionally, participate in the bioluminescence reaction within the protein-protein intermediate, influencing the kinetics of the reaction. Renilla coelenterazine-binding protein stores coelenterazine protecting it from oxidation and, being a calcium-regulated protein, links the luminescence response to a neural signal. Delivery of coelenterazine to luciferase within the putative CBP-luciferase complex remarkably enhances the bioluminescence quantum yield.

The above mentioned bioluminescence protein-protein complexes are characterized by being weak and transient with affinity constants $\mathrm{K}_{\mathrm{D}}$ in the millimolar range and higher. This provides its own set of impediments on how to detect and structurally characterize the interactions. So far none of the bioluminescence complexes have provided crystals with good diffraction, and in the best case, we are left with knowledge of the interaction surfaces derived from biophysical experiments including NMR, which could be mapped onto the crystal structures of individual proteins. Interaction restraints are input to a docking program to derive a number of lowest free energy structures representing the overall topology of the protein-protein complex. Although the highest limit of molecular size in NMR studies is constantly increasing, specifically defining interaction restraints with NOE NMR in the complexes with weak protein-protein interactions is still challenging, and therefore other NMR techniques such as residual dipolar couplings (RDC) and chemical shift perturbations (CSPs)-based docking, are quite important in the studies of these weak transient complexes (Wang et al., 2011).

Despite that the spatial structures available for several bioluminescence protein-protein complexes need more verification, some of their properties are obviously common. They all share the property of charge complementarity of the interaction surfaces, a relatively low number of hydrogen bonds and intermolecular contacts, and with interaction surface areas having values about average among the known protein-protein complexes. Another interesting similarity is that the interactions with antenna proteins are also governed by some intermediate events. In the bacterial system, a metastable luciferase-bound intermediate is required to increase the affinity to lumazine protein over the unreacted luciferase, and its breakdown promotes the complex dissociation. The photoprotein clytin from Clytia is triggered for conformational changes upon binding of $\mathrm{Ca}^{2+}$, followed by formation of a "high energy intermediate" which, it is proposed, might have a shifted protein conformation now a thousand times more appealing to Clytia GFP than clytin "before" or "after" the bioluminescence.

Bioluminescence protein-protein interactions are not confined to the ones discussed from the structural perspective in this review. Bacterial NADPH:FMN oxidoreductase delivers newly synthesized $\mathrm{FMNH}_{2}$ to luciferase within a protein-protein complex, complicating the organization of the protein-protein interaction network involved in the bioluminescence system of bacteria. In Renilla, the energy transfer mediating interaction is known to occur between luciferase and GFP and, even though the complex was reported to be cocrystallized (Loening et al., 2007), the structural basis for this interaction still remains unknown. It is of particular interest to know how the three proteins of the Renilla system, luciferase, CBP, and GFP, which are found in photocytes in approximately equal molar concentrations (Ward and Cormier, 1978), are organized and operate within a multi-protein complex.

\section{ACKNOWLEDGEMENTS}

The work was funded by "Fellowship for Young International Scientists" of Chinese Academy of Sciences. This work was supported by the National Natural Science Foundation of China (Grant Nos: 30870483, 31070660, 31021062 and 81072449), Ministry of Science and Technology of China (Nos. 2009DFB30310, 2009 CB918803 and 2011CB911103), CAS Research Grants (Nos. YZ200839 and KSCX2-EW-J-3).

\section{ABBREVIATIONS}

BLuc, bacterial luciferase; CA, coelenteramide; CBP, coelenterazinebinding protein; CZ, coelenterazine; CSY, fluorophore of Clytia GFP; CSD, chemical shift perturbation difference; FRET, Förster resonance energy transfer; GFP, green-fluorescent protein; HSQC, heteronuclear single quantum coherence spectroscopy; LumP, lumazine protein; NOE, Nuclear Overhauser effect; Rf, riboflavin; RLuc, Renilla luciferase; RMSD, root mean square deviation; YFP, yellowfluorescent protein

\section{REFERENCES}

Anderson, J.M., Charbonneau, H., and Cormier, M.J. (1974). Mechanism of calcium induction of Renilla bioluminescence. Involvement of a calcium-triggered luciferin binding protein. Biochemistry 13, 1195-1200.

Anderson, J.M., and Cormier, M.J. (1973). Lumisomes, the cellular site of bioluminescence in coelenterates. J Biol Chem 248, 2937-2943.

Arnold, K., Bordoli, L., Kopp, J., and Schwede, T. (2006). The SWISSMODEL workspace: a web-based environment for protein structure homology modelling. Bioinformatics 22, 195-201.

Baker, N.A., Sept, D., Joseph, S., Holst, M.J., and McCammon, J.A. (2001). Electrostatics of nanosystems: application to microtubules and the ribosome. Proc Natl Acad Sci USA 98, 10037-10041.

Baldwin, T.O., Treat, M.L., and Daubner, S.C. (1990). Cloning and expression of the luxY gene from Vibrio fischeri strain $Y-1$ in Escherichia coli and complete amino acid sequence of the yellow fluorescent protein. Biochemistry 29, 5509-5515.

Baldwin, T.O., and Ziegler, M.M. (1992). The biochemistry and molecular biology of bacterial bioluminescence. In: Chemistry and Biochemistry of Flavoenzymes III. Mueller F., ed. Boca Raton, Florida: CRC pRESS, 467-530. 
Berg, O.G., and von Hippel, P.H. (1985). Diffusion-controlled macromolecular interactions. Annu Rev Biophys Biophys Chem 14, 131-160.

Campbell, Z.T., Baldwin, T.O., and Miyashita, O. (2010). Analysis of the bacterial luciferase mobile loop by replica-exchange molecular dynamics. Biophys J 99, 4012-4019.

Campbell, Z.T., Weichsel, A., Montfort, W.R., and Baldwin, T.O. (2009). Crystal structure of the bacterial luciferase/flavin complex provides insight into the function of the beta subunit. Biochemistry $48,6085-6094$.

Charbonneau, H., and Cormier, M.J. (1979). Ca2+-induced bioluminescence in Renilla reniformis. Purification and characterization of a calcium-triggered luciferin-binding protein. J Biol Chem 254, 769-780.

Chatwell, L., Illarionova, V.A., Illarionov, B., Eisenreich, W., Huber, R., Skerra, A., Bacher, A., and Fischer, M. (2008). Structure of lumazine protein, an optical transponder of luminescent bacteria. $J$ Mol Biol 382, 44-55.

Cormier, M.J. (1978). Comparative biochemistry of animal systems. In: Bioluminescence in Action. Herring P.J., ed. London: Academic Press, 75-108.

Cormier, M.J., and Charbonneau, H. (1977). Isolation, properties and function of a calcium-triggered luciferin binding protein. In: Calcium Binding Proteins and Calcium Function. Wasserman H.R., ed. North-Holland: Elsevier, 481-489.

Cormier, M.J., Hori, K., and Anderson, J.M. (1974). Bioluminescence in coelenterates. Biochim Biophys Acta 346, 137-164.

Cormier, M.J., Lee, J., and Wampler, J.E. (1975). Bioluminescence: recent advances. Annu Rev Biochem 44, 255-272.

Cutler, M.W. (1995). Characterization and energy transfer mechanism of the green-fluorescent protein from Aequorea victoria. $\mathrm{PhD}$ thesis, Rutgers University, New Brunswick, NJ.

Cutler, M.W., and Ward, W.W. (1997). Spectral analysis and proposed model for GFP dimerization. In: Bioluminescence and Chemiluminescence: Molecular Reporting with Photons. Hastings J.W., Kricka L.J., and Stanley P.E., eds. New York: Wiley Liss, 596-599.

Daubner, S.C., Astorga, A.M., Leisman, G.B., and Baldwin, T.O. (1987). Yellow light emission of Vibrio fischeri strain Y-1: purification and characterization of the energy-accepting yellow fluorescent protein. Proc Natl Acad Sci U S A 84, 8912-8916.

de Vries, S.J., van Dijk, A.D.J., Krzeminski, M., van Dijk, M., Thureau, A., Hsu, V., Wassenaar, T., and Bonvin, A.M.J.J. (2007). HADDOCK versus HADDOCK: new features and performance of HADDOCK2.0 on the CAPRI targets. Proteins 69, 726-733.

DeLuca, M., Dempsey, M.E., Hori, K., Wampler, J.E., and Cormier, M. J. (1971). Mechanism of oxidative carbon dioxide production during Renilla reniformis bioluminescence. Proc Natl Acad Sci U S A 68, 1658-1660.

Deng, L., Vysotski, E.S., Markova, S.V., Liu, Z.-J., Lee, J., Rose, J., and Wang, B.-C. (2005). All three Ca2+-binding loops of photoproteins bind calcium ions: the crystal structures of calcium-loaded apo-aequorin and apo-obelin. Protein Sci 14, 663-675.

Dolinsky, T.J., Nielsen, J.E., McCammon, J.A., and Baker, N.A. (2004). PDB2PQR: an automated pipeline for the setup of Poisson-Boltzmann electrostatics calculations. Nucleic Acids Res 32, W665-W667.

Dominguez, C., Boelens, R., and Bonvin, A.M.J.J. (2003). HAD-
DOCK: a protein-protein docking approach based on biochemical or biophysical information. J Am Chem Soc 125, 1731-1737.

Dunlap, K., Takeda, K., and Brehm, P. (1987). Activation of a calciumdependent photoprotein by chemical signalling through gap junctions. Nature 325, 60-62.

Eckstein, J.W., Cho, K.W., Colepicolo, P., Ghisla, S., Hastings, J.W., and Wilson, T. (1990). A time-dependent bacterial bioluminescence emission spectrum in an in vitro single turnover system: energy transfer alone cannot account for the yellow emission of Vibrio fischeri Y-1. Proc Natl Acad Sci U S A 87, 1466-1470.

Fisher, A.J., Raushel, F.M., Baldwin, T.O., and Rayment, I. (1995). Three-dimensional structure of bacterial luciferase from Vibrio harveyi at $2.4 \mathrm{~A}$ resolution. Biochemistry 34, 6581-6586.

Fisher, A.J., Thompson, T.B., Thoden, J.B., Baldwin, T.O., and Rayment, I. (1996). The 1.5-A resolution crystal structure of bacterial luciferase in low salt conditions. J Biol Chem 271, 21956-21968.

Fogel, M., and Hastings, J.W. (1972). Bioluminescence: mechanism and mode of control of scintillon activity. Proc Natl Acad Sci U S A 69, 690-693.

Förster, T. (1960). Transfer mechanisms of electronic excitation energy. Radiat Res Suppl 2, 326-339.

Francisco, W.A., Abu-Soud, H.M., DelMonte, A.J., Singleton, D.A., Baldwin, T.O., and Raushel, F.M. (1998). Deuterium kinetic isotope effects and the mechanism of the bacterial luciferase reaction. Biochemistry 37, 2596-2606.

Haddock, S.H.D., Moline, M.A., and Case, J.F. (2010). Bioluminescence in the sea. Ann Rev Mar Sci 2, 443-493.

Hart, R.C., Matthews, J.C., Hori, K., and Cormier, M.J. (1979). Renilla reniformis bioluminescence: luciferase-catalyzed production of nonradiating excited states from luciferin analogues and elucidation of the excited state species involved in energy transfer to Renilla green fluorescent protein. Biochemistry 18, 2204-2210.

Harvey, E.N. (1952). Bioluminescence. New York: Acdademic Press, 649.

Hastings, J.W., Eberhard, A., Baldwin, T.O., Nicoli, M.Z., Cline, T.W., and Nealson, K.H. (1973). Bacterial bioluminescence: Mechanistic implications of active center chemistry of luciferase. In: Bioluminescence and Chemiluminescence. Cormier M.J., Hercules D.M., and Lee J., eds. New York: Plenum Publishing Co. 369-380.

Hastings, J.W., and Gibson, Q.H. (1963). Intermediates in the bioluminescent oxidation of reduced flavin mononucleotide. J Biol Chem 238, 2537-2554.

Hastings, J.W., and Morin, J.G. (1969). Calcium-triggered light emission in Renilla. A unitary biochemical scheme for coelenterate bioluminescence. Biochem Biophys Res Commun 37, 493- 498.

Hastings, J.W., and Nealson, K.H. (1977). Bacterial bioluminescence. Annu Rev Microbiol 31, 549-595.

Head, J.F., Inouye, S., Teranishi, K., and Shimomura, O. (2000). The crystal structure of the photoprotein aequorin at $2.3 \mathrm{~A}$ resolution. Nature 405, 372-376.

Holmquist, M. (2000). Alpha/Beta-hydrolase fold enzymes: structures, functions and mechanisms. Curr Protein Pept Sci 1, 209-235.

Inlow, J.K., and Baldwin, T.O. (2002). Mutational analysis of the subunit interface of Vibrio harveyi bacterial luciferase. Biochemistry $41,3906-3915$.

Inouye, S. (2007). Expression, purification and characterization of 
calcium-triggered luciferin-binding protein of Renilla reniformis. Protein Expr Purif 52, 66-73.

Inouye, S., and Tsuji, F.I. (1993). Cloning and sequence analysis of cDNA for the $\mathrm{Ca}(2+)$-activated photoprotein, clytin. FEBS Lett 315 , 343-346.

Jeffers, C.E., Nichols, J.C., and Tu, S.-C. (2003). Complex formation between Vibrio harveyi luciferase and monomeric NADPH:FMN oxidoreductase. Biochemistry 42, 529-534.

Jones, S., and Thornton, J.M. (1996). Principles of protein-protein interactions. Proc Natl Acad Sci U S A 93, 13-20.

Karkhanis, Y.D., and Cormier, M.J. (1971). Isolation and properties of Renilla reniformis luciferase, a low molecular weight energy conversion enzyme. Biochemistry 10, 317-326.

Kiel, C., Selzer, T., Shaul, Y., Schreiber, G., and Herrmann, C. (2004). Electrostatically optimized Ras-binding Ral guanine dissociation stimulator mutants increase the rate of association by stabilizing the encounter complex. Proc Natl Acad Sci U S A 101, 9223-9228.

Kulinski, T., Visser, A.J., O'Kane, D.J., and Lee, J. (1987). Spectroscopic investigations of the single tryptophan residue and of riboflavin and 7-oxolumazine bound to lumazine apoprotein from Photobacterium leiognathi. Biochemistry 26, 540-549.

Kumar, S., Harrylock, M., Walsh, K.A., Cormier, M.J., and Charbonneau, H. (1990). Amino acid sequence of the Ca2(+)-triggered luciferin binding protein of Renilla reniformis. FEBS Lett 268, 287-290.

Lee, J. (1993). Lumazine protein and the excitation mechanism in bacterial bioluminescence. Biophys Chem 48, 149-158.

Lee, J. (2008). Bioluminescence: the first 3000 years. [review] J Sib Fed U Biology 3, 194-205.

Lee, J., Gibson, B.G., O'Kane, D.J., Kohnle, A., and Bacher, A. (1992). Fluorescence study of the ligand stereospecificity for binding to lumazine protein. Eur J Biochem 210, 711-719.

Lee, J., O'Kane, D.J., and Gibson, B.G. (1989). Bioluminescence spectral and fluorescence dynamics study of the interaction of lumazine protein with the intermediates of bacterial luciferase bioluminescence. Biochemistry 28, 4263-4271.

Lee, J., O'Kane, D.J., and Visser, A.J. (1985). Spectral properties and function of two lumazine proteins from Photobacterium. Biochemistry $24,1476-1483$.

Lee, J., Wang, Y.Y., and Gibson, B.G. (1991). Electronic excitation transfer in the complex of lumazine protein with bacterial bioluminescence intermediates. Biochemistry 30, 6825-6835.

Levine, L.D., and Ward, W.W. (1982). Isolation and characterization of a photoprotein, "phialidin," and a spectrally unique green-fluorescent protein from the bioluminescent jellyfish Phialidium gregarium. Comp Biochem Physiol B Biochem Mol Biol 72, 77-85.

Li, L., Liu, X., Yang, W., Xu, F., Wang, W., Feng, L., Bartlam, M., Wang, L., and Rao, Z. (2008). Crystal structure of long-chain alkane monooxygenase (LadA) in complex with coenzyme FMN: unveiling the long-chain alkane hydroxylase. J Mol Biol 376, 453-465.

Liao, D.I., Wawrzak, Z., Calabrese, J.C., Viitanen, P.V., and Jordan, D.B. (2001). Crystal structure of riboflavin synthase. Structure 9, 399- 408.

Liu, Z.-J., Stepanyuk, G.A., Vysotski, E.S., Lee, J., Markova, S.V., Malikova, N.P., and Wang, B.-C. (2006). Crystal structure of obelin after $\mathrm{Ca} 2$ +-triggered bioluminescence suggests neutral coelenteramide as the primary excited state. Proc Natl Acad Sci U S A 103,
$2570-2575$

Liu, Z.-J., Vysotski, E.S., Chen, C.J., Rose, J.P., Lee, J., and Wang, B.-C. (2000). Structure of the Ca2 +-regulated photoprotein obelin at $1.7 \mathrm{~A}$ resolution determined directly from its sulfur substructure. Protein Sci 9, 2085-2093.

Lo Conte, L., Chothia, C., and Janin, J. (1999). The atomic structure of protein-protein recognition sites. J Mol Biol 285, 2177-2198.

Loening, A.M., Fenn, T.D., and Gambhir, S.S. (2007). Crystal structures of the luciferase and green fluorescent protein from Renilla reniformis. J Mol Biol 374, 1017-1028.

Loening, A.M., Fenn, T.D., Wu, A.M., and Gambhir, S.S. (2006). Consensus guided mutagenesis of Renilla luciferase yields enhanced stability and light output. Protein Eng Des Sel 19, $391-400$.

Lorenz, W.W., McCann, R.O., Longiaru, M., and Cormier, M.J. (1991). Isolation and expression of a cDNA encoding Renilla reniformis luciferase. Proc Natl Acad Sci U S A 88, 4438-4442.

Macheroux, P., Schmidt, K.U., Steinerstauch, P., Ghisla, S., Colepicolo, P., Buntic, R., and Hastings, J.W. (1987). Purification of the yellow fluorescent protein from Vibrio fischeri and identity of the flavin chromophore. Biochem Biophys Res Commun 146, 101-106.

Malikova, N.P., Visser, N.V., van Hoek, A., Skakun, V.V., Vysotski, E. S., Lee, J., and Visser, A.J.W.G. (2011). Green-fluorescent protein from the bioluminescent jellyfish Clytia gregaria is an obligate dimer and does not form a stable complex with the $\mathrm{Ca}(2+)$ discharged photoprotein clytin. Biochemistry 50, 4232-4241.

Markova, S.V., Burakova, L.P., Frank, L.A., Golz, S., Korostileva, K. A., and Vysotski, E.S. (2010). Green-fluorescent protein from the bioluminescent jellyfish Clytia gregaria: cDNA cloning, expression, and characterization of novel recombinant protein. Photochem Photobiol Sci 9, 757-765.

Matheson, I.B.C., and Lee, J. (1983). Kinetics of bacterial bioluminescence and the fluorescent transient. Photochem Photobiol 38, 231-240.

Matthews, J.C., Hori, K., and Cormier, M.J. (1977a). Purification and properties of Renilla reniformis luciferase. Biochemistry 16, 85-91.

Matthews, J.C., Hori, K., and Cormier, M.J. (1977b). Substrate and substrate analogue binding properties of Renilla luciferase. Biochemistry 16, 5217-5220.

Morin, J.G., and Hastings, J.W. (1971). Energy transfer in a bioluminescent system. J Cell Physiol 77, 313-318.

Morise, H., Shimomura, O., Johnson, F.H., and Winant, J. (1974). Intermolecular energy transfer in the bioluminescent system of Aequorea. Biochemistry 13, 2656-2662.

Morse, D., Pappenheimer, A.M. Jr, and Hastings, J.W. (1989). Role of a luciferin-binding protein in the circadian bioluminescent reaction of Gonyaulax polyedra. J Biol Chem 264, 11822-11826.

Nicolas, M.-T., Morse, D., Bassot, J.-M., and Hastings, J.W. (1991). Colocalization of luciferin binding protein and luciferase to the scintillons of Gonyaulax polyedra revealed by double immunolabeling after fast-freeze fixation. Protoplasma 160, 159-166.

O'Kane, D.J., Karle, V.A., and Lee, J. (1985). Purification of lumazine proteins from Photobacterium leiognathi and Photobacterium phosphoreum: bioluminescence properties. Biochemistry 24, 1461-1467.

O'Kane, D.J., and Prasher, D.C. (1992). Evolutionary origins of bacterial bioluminescence. Mol Microbiol 6, 443-449. 
O'Kane, D.J., Woodward, B., Lee, J., and Prasher, D.C. (1991). Borrowed proteins in bacterial bioluminescence. Proc Natl Acad Sci U S A 88, 1100-1104.

Ollis, D.L., Cheah, E., Cygler, M., Dijkstra, B., Frolow, F., Franken, S. M., Harel, M., Remington, S.J., Silman, I., Schrag, J., et al. (1992). The alpha/beta hydrolase fold. Protein Eng 5, 197-211.

Ormö, M., Cubitt, A.B., Kallio, K., Gross, L.A., Tsien, R.Y., and Remington, S.J. (1996). Crystal structure of the Aequorea victoria green fluorescent protein. Science 273, 1392-1395.

Petushkov, V.N., Gibson, B.G., and Lee, J. (1995). The yellow bioluminescence bacterium, Vibrio fischeri $Y 1$, contains a bioluminescence active riboflavin protein in addition to the yellow fluorescence FMN protein. Biochem Biophys Res Commun 211, 774-779.

Petushkov, V.N., Gibson, B.G., and Lee, J. (1996a). Direct measurement of excitation transfer in the protein complex of bacterial luciferase hydroxyflavin and the associated yellow fluorescence proteins from Vibrio fischeri Y1. Biochemistry 35, 8413-8418.

Petushkov, V.N., Ketelaars, M., Gibson, B.G., and Lee, J. (1996b). Interaction of Photobacterium leiognathi and Vibrio fischeri $\mathrm{Y} 1$ luciferases with fluorescent (antenna) proteins: bioluminescence effects of the aliphatic additive. Biochemistry 35, 12086-12093.

Petushkov, V.N., and Lee, J. (1997). Purification and characterization of flavoproteins and cytochromes from the yellow bioluminescence marine bacterium Vibrio fischeri strain Y1. Eur J Biochem 245, 790-796.

Prudêncio, M., and Ubbink, M. (2004). Transient complexes of redox proteins: structural and dynamic details from NMR studies. J Mol Recognit 17, 524-539.

Reichmann, D., Rahat, O., Cohen, M., Neuvirth, H., and Schreiber, G. (2007). The molecular architecture of protein-protein binding sites. Curr Opin Struct Biol 17, 67-76.

Remington, S.J. (2006). Fluorescent proteins: maturation, photochemistry and photophysics. Curr Opin Struct Biol 16, 714-721.

Sato, Y., Shimizu, S., Ohtaki, A., Noguchi, K., Miyatake, H., Dohmae, N., Sasaki, S., Odaka, M., and Yohda, M. (2010). Crystal structures of the lumazine protein from Photobacterium kishitanii in complexes with the authentic chromophore, 6,7-dimethyl- 8-(1'-Dribityl) lumazine, and its analogues, riboflavin and flavin mononucleotide, at high resolution. J Bacteriol 192, 127-133.

Schneidman-Duhovny, D., Inbar, Y., Nussinov, R., and Wolfson, H.J. (2005). PatchDock and SymmDock: servers for rigid and symmetric docking. Nucleic Acids Res 33, W363-W367.

Schreiber, G., Shaul, Y., and Gottschalk, K.E. (2006). Electrostatic design of protein-protein association rates. Methods Mol Biol 340, 235-249.

Schultz, L.W., Liu, L., Cegielski, M., and Hastings, J.W. (2005). Crystal structure of a $\mathrm{pH}$-regulated luciferase catalyzing the bioluminescent oxidation of an open tetrapyrrole. Proc Natl Acad Sci U S A 102, 1378-1383.

Sheinerman, F.B., Norel, R., and Honig, B. (2000). Electrostatic aspects of protein-protein interactions. Curr Opin Struct Biol 10, 153-159.

Shimomura, O. (1997). Membrane permeability of coelenterazine analogues measured with fish eggs. Biochem J 326, 297-298.

Shimomura, O. (2006). Bioluminescence: chemical principles and methods. Singapore: World Scientific, 470.

Shimomura, O., and Teranishi, K. (2000). Light-emitters involved in the luminescence of coelenterazine. Luminescence 15, 51-58.

Sinclair, J.F., Waddle, J.J., Waddill, E.F., and Baldwin, T.O. (1993). Purified native subunits of bacterial luciferase are active in the bioluminescence reaction but fail to assemble into the alpha beta structure. Biochemistry 32, 5036-5044.

Sparks, J.M., and Baldwin, T.O. (2001). Functional implications of the unstructured loop in the (beta/alpha)(8) barrel structure of the bacterial luciferase alpha subunit. Biochemistry 40, 15436-15443.

Stepanyuk, G.A., Liu, Z.-J., Vysotski, E.S., Lee, J., Rose, J.P., and Wang, B.-C. (2009). Structure based mechanism of the $\mathrm{Ca}(2+)-$ induced release of coelenterazine from the Renilla binding protein. Proteins 74, 583-593.

Titushin, M.S. (2009). Protein-protein interactions in the bioluminescence systems of coelenterates Renilla muelleri and Clytia gregaria. PhD thesis. Institute of Biophysics SB RAS, Krasnoyarsk 660036, Russia.

Titushin, M.S., Feng, Y., Stepanyuk, G.A., Li, Y., Markova, S.V., Golz, S., Wang, B.-C., Lee, J., Wang, J., Vysotski, E.S., et al. (2010). NMR-derived topology of a GFP-photoprotein energy transfer complex. J Biol Chem 285, 40891-40900.

Titushin, M.S., Markova, S.V., Frank, L.A., Malikova, N.P., Stepanyuk, G.A., Lee, J., and Vysotski, E.S. (2008). Coelenterazine-binding protein of Renilla muelleri: cDNA cloning, overexpression, and characterization as a substrate of luciferase. Photochem Photobiol Sci 7, 189-196.

Vaynberg, J., and Qin, J. (2006). Weak protein-protein interactions as probed by NMR spectroscopy. Trends Biotechnol 24, 22-27.

Vervoort, J., O'Kane, D.J., Müller, F., Bacher, A., Strobl, G., and Lee, J. (1990). 13C and 15N NMR studies on the interaction between 6,7-dimethyl-8-ribityllumazine and lumazine protein. Biochemistry 29, 1823-1828.

Visser, A.J., and Lee, J. (1982). Association between lumazine protein and bacterial luciferase: direct demonstration from the decay of the lumazine emission anisotropy. Biochemistry 21, 2218-2226.

Visser, A.J., Hoek, A., Visser, N.V., Lee, Y., and Ghisla, S. (1997). Time-resolved fluorescence study of the dissociation of FMN from the yellow fluorescence protein from Vibrio fischeri. Photochem Photobiol 65, 570-575.

Vysotski, E. S., and Lee, J. (2007). Bioluminescent mechanism of $\mathrm{Ca} 2+$-regulated photoproteins from three-dimensional structures. In: Luciferases and Fluorescent Proteins: Principles and Advances in Biotechnology and Bioimaging. Viviani V.R. and Ohmiya Y., eds. Kerala, India: Transworld Pesearch Network, 19-41.

Wachter, R.M. (2007). Chromogenic cross-link formation in green fluorescent protein. Acc Chem Res 40, 120-127.

Wang, X., Lee, H.-W., Liu, Y., and Prestegard, J.H. (2011). Structural NMR of protein oligomers using hybrid methods. J Struct Biol 173, 515-529.

Ward, W.W. (1979). Energy transfer processes in bioluminescence. In: Photochemical and Photobiological Reviews. Smith K.C., ed. New York: Plenum Press, 1-57.

Ward, W.W., and Cormier, M.J. (1976). In vitro energy transfer in Renilla bioluminescence. J Phys Chem 80, 2289-2291.

Ward, W.W., and Cormier, M.J. (1978). Energy transfer via proteinprotein interaction in Renilla bioluminescence. Photochem Photobiol 27, 389-396. 
Ward, W.W., and Cormier, M.J. (1979). An energy transfer protein in coelenterate bioluminescence. Characterization of the Renilla green-fluorescent protein. J Biol Chem 254, 781-788.

Wilson, T., and Hastings, J.W. (1998). Bioluminescence. Annu Rev Cell Dev Biol 14, 197-230.

Woo, J., Howell, M.H., and von Arnim, A.G. (2008). Structure-function studies on the active site of the coelenterazine-dependent luciferase from Renilla. Protein Sci 17, 725-735.

Wu, P., and Brand, L. (1994). Resonance energy transfer: methods and applications. Anal Biochem 218, 1-13.

Zuiderweg, E.R.P. (2002). Mapping protein-protein interactions in solution by NMR spectroscopy. Biochemistry 41, 1-7. 